
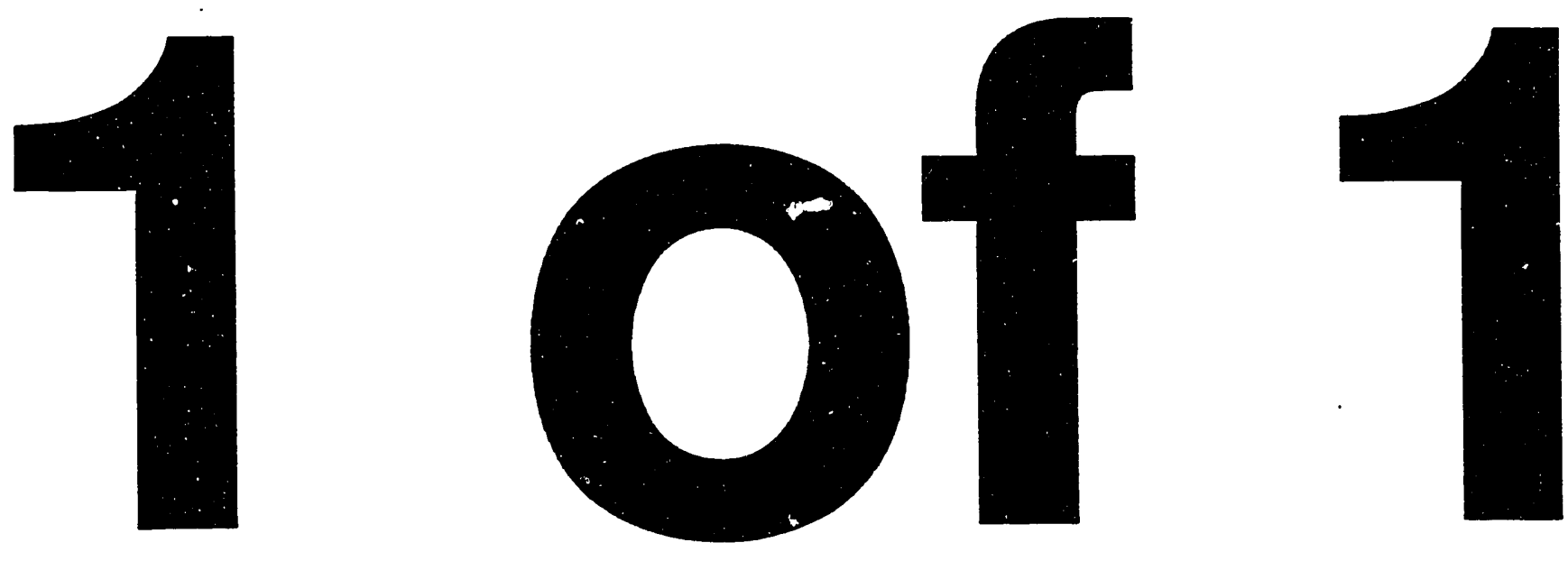
SAND93-2158

Unlimited Release

Printed September 1993
Distribution

Category UC-722

\title{
Accident Response Group (ARG) Containers for Recovery of Damaged Warheads (U)
}

\author{
Allen R. York, II \\ Advanced Systems Department \\ John P. Hoffman \\ System Studies Department \\ Sandia National Laboratories \\ Albuquerque, NM 87185
}

Abstract (U)

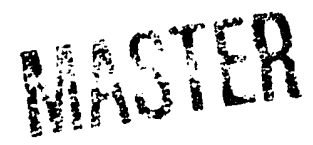

This report provides an overview of the containers that are currently stored at Pantex and available for use in response to an accident or for use in any other application where a sealed containment vessel and accident resistant overpack may be needed. 
1 INTRODUCTION

2 CONTAINER DESCRITPIONS $\quad 6$

2.1 Outer Drum $\quad 6$

2.2 Containment Vessel $\quad 7$

2.3 Contents $\quad 7$

2.4 Assembly Configurations $\quad 7$

3 STRUCTURAL CAPABILITY $\quad 8$

3.1 Containment Vessel - Internal Pressure $\quad 8$

3.2 Impact

3.3 Puncture

4 THERMAL CAPABILITY

4.1 Normal Conditions

4.2 Accident Conditions

5 DOT 7A REQUIREMENTS

5.1 General Requirements

5.2 Specific Requirements

5.3 Water Spray $(\S 173.465(\mathrm{~b})) \quad 12$

5.4 Free Drop $(\S 173.465(\mathrm{c}))$

5.5 Compression $(\$ 173.465(\mathrm{~d})) \quad 12$

5.6 Penetration $(\S 173.465(\mathrm{e})) \quad 13$

6 DEFINITIONS

7 REFERENCES

Appendix A -Pressure Calculations $\quad 14$

Appendix B -Containment Vessel Fabrication Drawings $\quad 21$

Appendix C -Impact Analyses and Other Data

Appendix D -Memo from M.A. Kincy on Weapon Recovery Containers

Appendix E-Memo from Kay Matsumoto (LANL) on ARG Thermal Modeling 42

Appendix F -Containment Vessel Assembly and Leak Test Instructions 45

8 DISTRIBUTION $\quad 51$ 
Figure

Figure 1. M511 \& CV $14 \times$ 57-Configuration 1

Figure 2. M511 \& CV 18 x 57-Configuration 2

8

Figure 3. M483 \& CV 24x110-Configuration 3

8

Figure 4. T3 \& CV $18 \times$ 57-Configuration 4

8

Figure 5. Bottom Drop Energy Analysis

10

Figure 6. Thermal Response of Payload

11

Figure 7. Thermal Test Configuration

Table

Page

Table 1. Container Configurations $\quad 7$

$\begin{array}{ll}\text { Table 2. Weights } & 7\end{array}$

Table 3. Vessel Body Internal Pressure Capability $\quad 8$

Table 4. Vessel Internal Pressure Capability 9

Table 5. 4-foot Side and Bottom Impact Analyses $\quad 10$

Table 6. 30-foot Side and Bottom Impact Analyses $\quad 10$

Table 7. Pressure Loading due to Compression $\quad 13$ 


\section{Accident Response Group \\ (ARG) Containers for \\ Recovery of Damaged \\ Warheads}

\section{INTRODUCTION}

This report describes the containers that are currently available for recovery of damaged warheads from the field. These containers consist of a steel outer drum that is filled with rigid polyurethane foam that contains a sealed stainless steel inner containment vessel (CV). The damaged warhead is packaged inside the sealed CV for transportation. Although this report describes the containers as utilizing a sealed inner vessel, the use of the outer drum alone to package a warhead may be acceptable in certain situations.

In some cases it may be necessary for these containers to meet Department of Transportation (DOT) Type 7A packaging requirements. The specification for DOT Type 7A packagings is listed in 49 CFR 178.350.' The containers described here meet DOT 7A test requirements as specified in 49 CFR 173.465. This report shows compliance with the $7 \mathrm{~A}$ test requirements by tests, engineering evaluation, and comparative data.

In the event that one of these containers is used for recovery of a damaged warhead, the quantity of material will most likely be greater than an $A_{1}$ or $A_{2}$ quantity (Type A quantity) and may require a Type $B$ packaging. However, a return shipment of a damaged warhead may be designated a shipment in the national interest as described in DOE/AL Supplemental Directive $5610.1{ }^{2}$ and may not require a certified Type $B$ package. This report is not a Safety Analysis Report. It is not our intent to obtain Type B certification for these containers even though they may meet Type B test requirements. This report's purpose is to describe how the containers are constructed and used and to discuss their structural and thermal capabilities. This report may be used by the personnel making the decision of how to return a damaged warhead from the field to judge whether or not these containers would be adequate for the particular scenario encountered.

These containers are intended as an interim solution to the ARGs transportation needs. Developments are currently underway at Sandia to procure the next generation ARG container(s) whose performance and fabrication pedigree will be more completely documented.

\section{CONTAINER DESCRITPIONS}

There are six pieces of hardware available for packaging damaged warheads. There are three different outer drum designs and three different CV designs.

\subsection{Cuter Drum}

Two of the outer drum designs, designated the M511 and M483, were designed for shipping Army nuclear warhead sections. Both of these drums are constructed from carbon steel and are of the "clam-shell" type. That is, they are used in a horizontal configuration, and the drum splits into two halves from the centerine. The two halves are bolted together with a flange around the centerline. A thin layer of ceramic fiber insulation lines the inside diameter of the drum. Rigid polyurethane foam $\left(5 \mathrm{lb} / \mathrm{ft}^{3}\right)$ is cut to fit inside the drums and carry the appropriate $\mathrm{CV}$ and contents. The other drum design, designated T3, is a 304 stainless steel drum with a bolted lid at the top of the drum. The drum is integrally constructed with rigid polyurethane foam $\left(12 \mathrm{lb} / \mathrm{ft}^{3}\right)$ surrounding a cavity that holds the $\mathrm{CV}$. 


\subsection{Containment Vessel}

The three CV designs are similar but vary in size. They are constructed from standard ASME-type 304 stainless steel pipe and ellipsoidal heads. The lids of these CVs incorporate a valve and quick connect for backfilling and gas sampling. This feature is obtained by using lids from the H1616-1 container. $^{3}$

The O-ring grooves on all three CVs are standard sizes, so any type of O-ring (Viton, Butyl, Nitrile, etc.) may be used that would be most appropriate to the particular damage scenario. Instructions for $\mathrm{CV}$ assembly are listed in Appendix E.

\subsection{Contents}

The specific contents and condition of the contents can not be determined prior to use of the containers because it will be in response to an accident. Accident response group personnel will attempt to stabilize the warhead so that it is as safe as an undamaged warhead from a nuclear and conventional explosive standpoint prior to being packaged in the transportation container.

The method of securing the warhead in the CV will be determined after the condition of the damaged warhead has been established. Various methods include placing the contents in the desired location and pouring polyurethane foam or an RTV-type compound around the contents or using precut foam or plastic for support.

\subsection{Assembly Configurations}

These transportation containers consist of two major components, the outer protective drum and the CV. In some cases these components may be interchanged. Table 1 lists the possible shipping configurations of these containers.
Table 1. Container Configurations

\begin{tabular}{|c|c|c|c|}
\hline Config. & $\begin{array}{l}\text { Outer Drum } \\
\text { Designator }\end{array}$ & $\begin{array}{c}\text { Containment } \\
\text { Vessel } \\
\text { Designator } \\
(\varnothing \times \mathrm{L}, \text { in. })\end{array}$ & $\begin{array}{c}\text { CV } \\
\text { Drawing } \\
\text { Title }^{a}\end{array}$ \\
\hline 1 & M511 & CV $14 \times 57$ & T3 \\
\hline 2 & M511 & CV $18 \times 57$ & T4 \\
\hline 3 & M483 & CV $24 \times 110$ & S7 \\
\hline 4 & $\mathrm{~T} 3$ & CV $14 \times 57$ & T3 \\
\hline
\end{tabular}

a. Sandia fabrication drawing titles.

The configuration numbers listed in Table 1 are used throughout this report referring to the specific combination of outer drum and $\mathrm{CV}$ as listed.

Table 2. Weights

\begin{tabular}{|c|c|c|c|c|}
\hline config... & $\begin{array}{c}1 \\
\text { (M511) }\end{array}$ & $\begin{array}{c}2 \\
\text { (M511) }\end{array}$ & $\begin{array}{c}3 \\
\text { (M483) }\end{array}$ & $\begin{array}{c}4 \\
\text { (T3) }\end{array}$ \\
\hline \hline $\begin{array}{c}\text { Outer } \\
\text { drum }\end{array}$ & 900 & 900 & 2000 & 300 \\
\hline Foam & 251 & 209 & 624 & 190 \\
\hline $\begin{array}{c}\text { Cont. } \\
\text { vessel }\end{array}$ & 203 & 380 & 712 & 203 \\
\hline Contents & 450 & 525 & 2300 & 450 \\
\hline Other & 100 & 150 & 200 & 100 \\
\hline Total (lb) & 1904 & 2164 & 5836 & 1243 \\
\hline
\end{tabular}

Figure 1 through Figure 4 illustrates the four container configurations that are possible. The CV $14 \times 57$ vessel may be used in the M483 or T3 outer drums. 


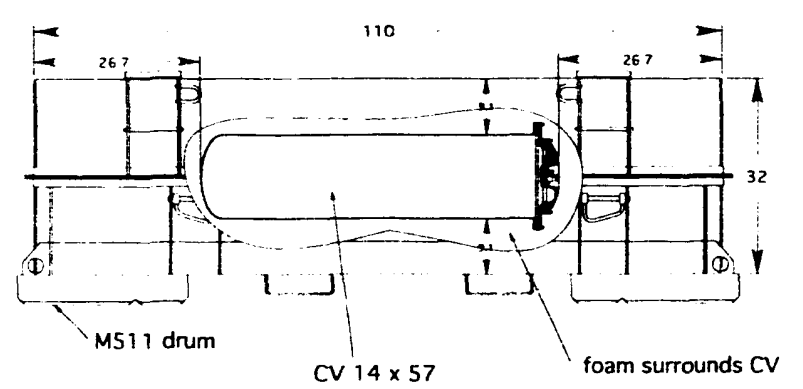

Figure 1. M511 \& CV 14 x 57-Configuration 1

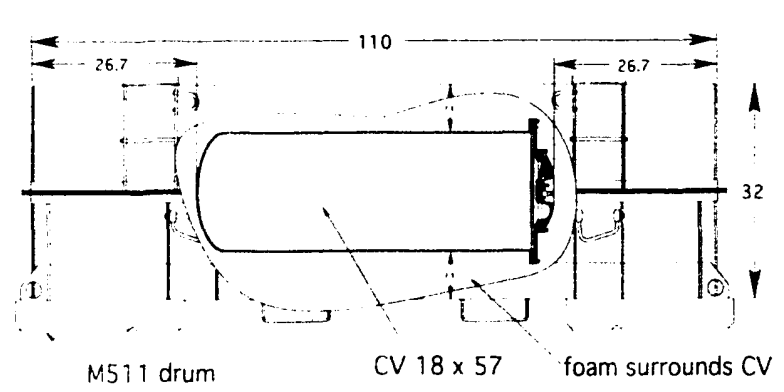

Figure 2. M511 \& CV $18 \times$ 57-Configuration 2

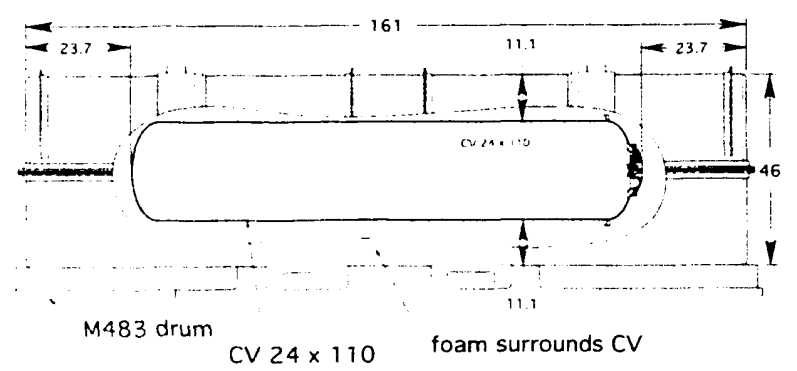

Figure 3. M483 \& CV 24x 110-Configuration 3

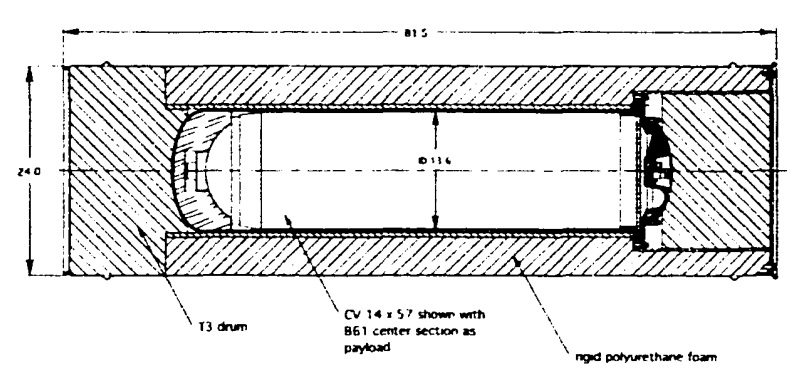

Figure 4. T3 \& CV $18 \times$ 57-Configuration 4

\section{STRUCTURAL CAPABILITY}

\subsection{Containment Vessel - Internal Pressure}

Table 3 lists the internal pressure capability based on the geometry of the cylindrical and ellipsoidal portions calculated using Section III Division I of the ASME boiler and Pressure Vessel Code. The detailed calculations can be found in Appendix A. Fabrication drawings for each of the CVs are in Appendix B.

Table 3. Vessel Body Internal Pressure Capability

\begin{tabular}{|c|c|c|}
\hline CV & $\begin{array}{c}\text { Vessel Body } \\
\text { Max. Allowable } \\
\text { Working } \\
\text { Pressure (psig) }\end{array}$ & $\begin{array}{c}\text { Nominal } \\
\text { Viall } \\
\text { Thickness } \\
\text { (in.) }\end{array}$ \\
\hline \hline CV $14 \times 57$ & 432 & 0.188 \\
\hline CV $18 \times 57$ & 447 & 0.25 \\
\hline CV $24 \times 110$ & 334 & 0.25 \\
\hline
\end{tabular}

Since vessels CV 14 x 57 and CV 18 × 57 have flat-type lids the stresses induced by pressure will be higher than in an ellipsoidal head. Therefore, the absolute maximum allowable working pressure is lower than that for the vessel alone. A similar analysis is done for $\mathrm{CV}$ $24 \times 110$ except the flat portion is considered to be the H1616 lid. Maximum internal pressures are listed in Table 4 and include a 
safety factor of $\geq 1.5$ against yield.

Table 4. Vessel Internal Pressure Capability

\begin{tabular}{|c|c|c|}
\hline $\mathrm{CV}$ & $\begin{array}{c}\text { Maximum } \\
\text { Allowable } \\
\text { Working Pressure } \\
\text { (psig) }\end{array}$ & $\begin{array}{c}\text { Proof } \\
\text { Pressure } \\
\text { (psig) }\end{array}$ \\
\hline CV $14 \times 57$ & 125 & 185 \\
\hline CV $18 \times 57$ & 77 & 115 \\
\hline CV $24 \times 110$ & 113 & 170 \\
\hline
\end{tabular}

All three of the CVs were pressure proof tested to the pressure listed in Table 4 (ref memo in Appendix A). Following the pressure proof test, the containment boundary of the vessels were helium leak tested and were leaktight.

\subsection{Impact}

All of the container configurations provide significant accident protection. The foam contained within the outer drum and surrounding the $\mathrm{CV}$ deforms during impact to dissipate the kinetic energy generated during the free fall.

Appendix $\mathrm{C}$ contains impact analyses (calculated on a spreadsheet) for a four and 30foot drop in a side and bottom drop configuration. These are static analyses that calculate the amount of foam deformation required to dissipate all of the drop energy. The strength added by the outer drum is ignored.

The container weight and assumed foam strength are listed in the spreadsheet.

The bottom drop calculation is made assuming that the mass contributing to the kinetic energy is the sum of the masses of the CV and contents and the foam above and below the CV. The area of foam crushed is assumed to be equivalent to the cross-sectional area of the
$\mathrm{CV}$ as illustrated in Figure 5.

The amount of foam, $d$, needed to dissipate the energy is found as follows.

$$
\begin{gathered}
E_{T D}=\frac{1}{2} m v^{2}=F d=S_{F} A_{C} d \\
d=\frac{E_{T D}}{S_{F} A_{C}}
\end{gathered}
$$

where,

$m$ is mass,

$v$ is impact velocity,

$d$ is the amount of foam needed (thickness),

$E_{T D}$ is the total drop energy,

$S_{F}$ is the strength of the foam (force/area), $A_{C}$ is the crush area.

The side drop calculations are similar. The area crushed is assumed to be the area under the CV or the length times the diameter of the vessel.

The physical mechanisms involved in dissipating the drop energy are more complex than can be accounted for in these simple analyses. The foam is actually crushed from both sides (the target side and CV side), and the dynamic strength is higher than the static strength. Also, the strength of the foam increases nonlinearly with increasing strain, and interactions with foam exterior to diameter "d" (Figure 5) affect the dissipation of energy. 


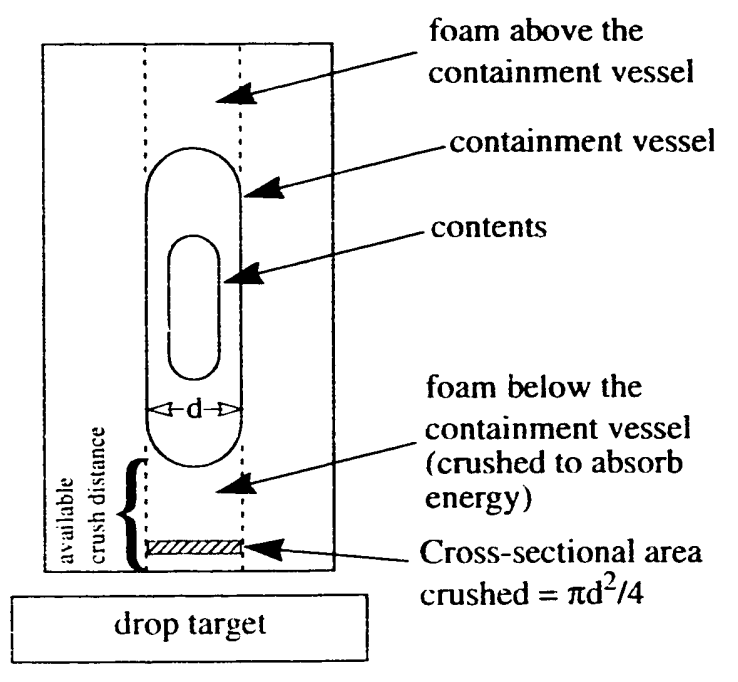

Figure 5. Bottom Drop Energy Analysis

As long as lockup of the foam is avoided ant confinement of the foam is maintained by the outer drum, these analyses provide a means for conservatively estimating impact capability. That is, the impact is complete prior to foam lockup when extremely high forces are transmitted and absorbed by the CV. These high forces due to lockup are more likely to severely damage the $\mathrm{CV}$ and break its seal than the much lower forces created while crushing the foam at lower percent strain.

Table 5 lists the results from Appendix $\mathrm{C}$ for the four-foot drop. The "req." column is the amount of foam required in inches, and the "avail." column lists the amount of foam available for each configuration. There is a large margin in each of the cases.

Table 5. 4-foot Side and Bottom Impact Analyses

\begin{tabular}{|c|c|c|c|c|}
\hline Config. & 1 & 2 & 3 & 4 \\
\hline \hline bottom req. & 1.7 & 1.5 & 2.5 & 0.3 \\
\hline bottom avail. & 26 & 26 & 30 & 11.5 \\
\hline side req. & 0.4 & 0.4 & 0.5 & 0.07 \\
\hline
\end{tabular}

Table 5. 4-foot Side and Bottom Impact Analyses (Continued)

\begin{tabular}{|c|c|c|c|c|}
\hline Config. & 1 & 2 & 3 & 4 \\
\hline \hline side avail. & $?$ & 7 & 11 & 5 \\
\hline
\end{tabular}

Table 6 lists similar quantities for the 30-foot drop. There is also quite a margin for the 30foot drop.

Table 6. 30-foot Side and Bottom Impact Analyses

\begin{tabular}{|c|c|c|c|c|}
\hline Config. & 1 & 2 & 3 & 4 \\
\hline \hline bottom req. & 13.0 & 11.0 & 18.6 & 2.5 \\
\hline bottom avail. & 26 & 26 & 30 & 11.5 \\
\hline side req. & 2.7 & 2.9 & 3.4 & 0.5 \\
\hline side avail. & 9 & 7 & 11 & 5 \\
\hline
\end{tabular}

Other configurations such as "cg over corner" and "slapdown" are more difficult to analyze. In a cg over corner srientation the foam crush area varies, and in a slapdown orientation two sides of the containicr are crushed, and the crush area is also variable. Appendix D contains a memo that discusses the impact capabilities of the M483 and M511 container (configurations $1,2, \& 3$ ). The impact analyses here and in Appendix D have the same conclusion that each container can withstand the 30-foot impact although the analyses here may be more conservative.

Also, Appendix D discusses the results from a 30 -foot drop test with a M483 outer container and the CV $24 \times 110$ vessel. The drop orientation was cg over corner, and the CV had no visible damage and was leaktight after the drop test. 


\subsection{Puncture}

The memo in Appendix D st ates that the M483 and M511 outer containers, configurations 1, 2 or 3 , would be punctured in a Type $B$ puncture test. Configuration 4 with the T3 outer drum might also suffer a punctured outer drum in the puncture test. It has not been determined if these containers could survive (remain leaktight) the fire test after being punctured.

\section{THERMAL CAPABILITY}

\subsection{Normal Conditions}

Analyses have been performed by Los Alamos National Laboratory. A summary memo is included in Appendix $E$ that describes normal and accident condition analyses that have been conducted.

\subsection{Accident Conditions}

Maximum $\mathrm{CV}$ temperatures are estimated to be below $300^{\circ} \mathrm{F}$ in a Type B fire environment. Elastomeric seals are normally not affected by these temperatures for relatively short periods of time. $^{4}$

In addition to the information presented in Appendix D, Figure 6 shows the thermal response of mock-up payloads in containers subjected to a one hour radiant heat test at an environment temperature of $1850^{\circ} \mathrm{F}$. ${ }^{*}$ These containers are similar in design to $\mathrm{T} 3$, configuration 4 , and might be used to predict the performance of configuration 4 in a similar fire environment.

The T3 outer drum is the same diameter as S5, but T3 is larger in height and the combination of payload and contents weigh more than the payload in S5. The steel thickness (16-gauge) is the same for both containers. Intumescent polyurethane foam with density of $12 \mathrm{lb} / \mathrm{ft}^{3}$ is used on test units S2 and S5 and outer drum

* Test conducted at Sandia's Area III radiant heat facility.
T3. T3 does not use ceramic fiber insulation as S2 and 55 do. The S2 and S5 container configurations with relevant dimensions are illustrated in Figure 7.

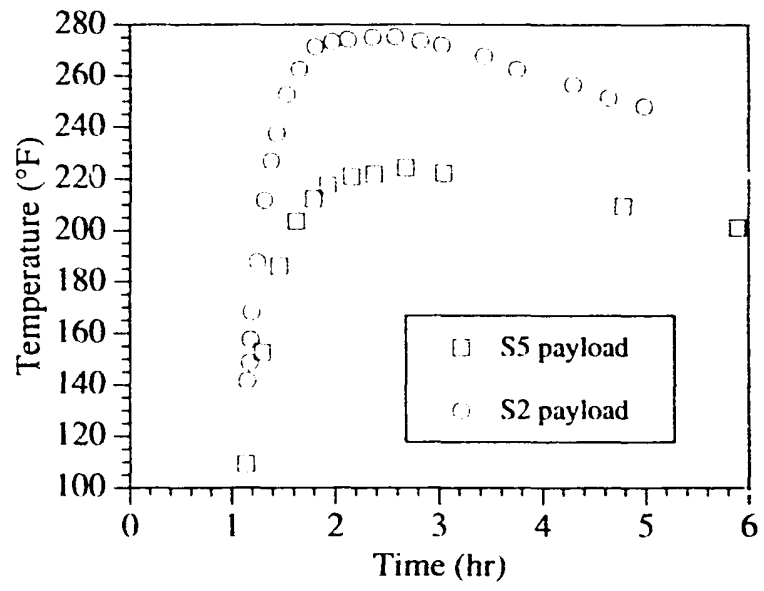

Figure 6. Thermal Response of Payload

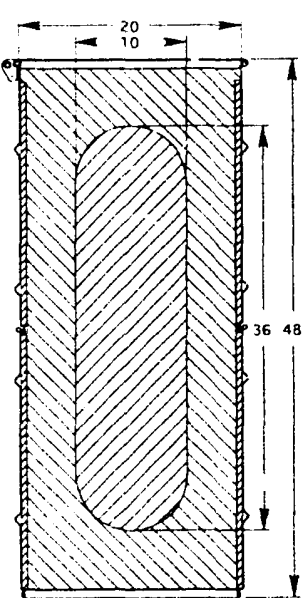

S2 Weight: $460 \mathrm{lb}$ Payload wt: 25 ? tb 12 pcf foam

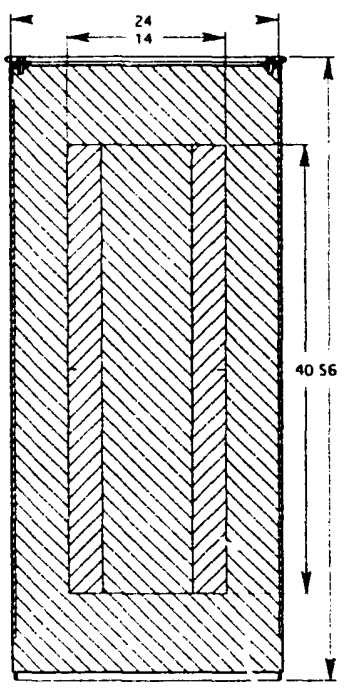

S5 Weight: 720 ib Payloas wt: 400 ib 12 pcf foam
Figure 7. Thermal Test Configuration

\section{DOT 7A REQUIREMENTS}

\subsection{General Requirements}

General requirements are listed in 49 CFR 173.24. The four configurations discussed here 
meet all general requirements of $\$ 173.24$ except:

1) In an accident recovery it may not be possible to meet requirement $\S(a)(3)$ which states that "there will be no mixture of gases or vapors in the package which could, through any credible spontaneous increase of heat or pressure, or through an explosion, significantly reduce the effectiveness of the packaging."

2) Since the containers will be transported exclusively by DOE personnel and since all of the contents can not be determined prior to the use of the container (which may determine if it can rigorously meet all DOT $7 \mathrm{~A}$ requirements), the containers will not be marked externally as described in $\$(c)(1)$.

If $\$ 173.24(a)(3)$ is met, then it would be the shippers responsibility to mark the containers externally as required in $\$(c)(1)$.

\subsection{Specific Requirements}

Paragraph 173.465 of Title 49 CFR "Type A packaging tests" lists the iests required for Type A packages. This paragraph states that "the proposed packaging with proposed contents must be capable of withstanding the tests prescribed in this section One prototype may he used for all tests it the requirements of paragraph (b) / water spray test/ of this section are complied with." The Type A acceptance criteria during and following the tests is that the integrity of the packaging, or of the packaging and its shielding, shall be retained to an extent such that there is no loss or dispersal of radioactive contents and no significant increase in radiation levels at the surface of the package. ${ }^{*}$ More stringent requirements are imposed here requiring that the $\mathrm{CV}$ be leaktight following the tests. This section will provide evidence that all 7A test requirements can be met by these packages.

\footnotetext{
* This comes from 49 CFR 173.412 and 173.463
}

\subsection{Water Spray $(\$ 173.465(b))$}

The water spray test will not cause any significant detrimental effects to the packagings that may reduce their ef ectiveness to withstand the drop, compression, and penetration tests that follow. The outer drums of the containers are all-metal construction. The impact limiting material is closed-cell rigid polyurethane foam that will retain only a few percent water in the unlikely event that it is directly exposed to water. The CVs are constructed from 304 stainless steel and are leaktight; therefore, water is of no concern here.

This requirement exists to mainly address cardboard or wood packages so it makes sunse that it would not affect these much stronger containers.

\subsection{Free Drop $(\$ 173.465(\mathrm{c}))$}

Since all of these containers weigh less than $11000 \mathrm{lb}$, the free drop requirement is to drop the packaging from four feet onto a hard essentially unyielding target. The discussion in Section 3.2 provides evidence that any of these container configurations will pass a four-foot drop test without significant damage. The forces imparted to the steel CV will be minimal for a four-foot drop. Also, one test Was completed with container coniguration 3 from 30-feet in a cg over corner orientation, and the $\mathrm{CV}$ remained leaktight and the contents (B83 mock-up) were not damaged.

\subsection{Compression $(\$ 173.465(\mathrm{~d}))$}

These containers do not have a facility for stacking and will not be stacked when used.

In each case the "5 times the container weight" loading requirement is larger than the " 265 psf' loading requirement. If converted to a pressure loading distributed over the top surface (1/2 the total surface area), the maximum loading is small. Table 7 lists the calculated loads. 
Table 7. Pressure Loading due to Compression

\begin{tabular}{|c|c|c|c|c|}
\hline Config. & 1 & 2 & 3 & 4 \\
\hline \hline Tot. Wt. & 1904 & 2164 & 5836 & 1243 \\
\hline $\begin{array}{c}5 x \text { wt. } \\
\text { (psi) }\end{array}$ & 2.8 & 3.1 & 4.0 & 3.2 \\
\hline
\end{tabular}

5.6 Penetration ( $\$ 173.465(\mathrm{e}))$

Metal outer drums are not affected significantly by the drop of a $13.2 \mathrm{lb}$ bar from 1 meter. Tests conducted on the $\mathrm{H} 1616$ which uses 16-gauge ( 0.06 in.) steel for the outer drum suffered only small dents the diameter of the penetration bar. The outer drum for configuration 3 uses 16-gauge steel while the M483 and M511 use thicker 14-gauge (0.075 in.) material that would resist denting more than the lighter material.

\section{DEFINITIONS}

Containment vessel. A stainless steel vessel sealed with elastomeric O-rings that provides containment of hazardous material. The CV can be backfilled with any type of gas to provide a benign environment for the contents.

Outer Drunı. A structure that surrounds the CV providing mechanical and thermal protection as well as a means to handle and secure the packaging.

Leaktight. No detectable leak of helium to a sensitivity of $5 \times 10^{-8} \mathrm{std} \mathrm{cc/s}$.

Type A Packaging. A packaging designed to retain the integrity of containment and shielding required by this part under normal conditions of transport as demonstrated by the tests set forth in 49 CFR 173.465 or 173.466 as appropriate. ${ }^{\prime}$
Type B package. A package meeting $10 \mathrm{CFR}$ 71 Type $B$ requirements.

Package. Packaging together with its radioactive contents.

Packaging. The assembly of components necessary to ensure compliance with the packaging requirement of $10 \mathrm{CFR} 71$.

Container. A generic term meaning package or packaging depending on the context.

\section{REFERENCES}

1 Title 49 of the Code of Federal Regulations (49 CFR).

2 US DOE Order 5610.1, Packaging and Transportation of Components and Special Assemblies Associated with the Nuclear Weapons Program, October 1, 1992.

3 Offsite Tranpsoration Certificate, No. DOE/AL/91001/B(U), US DOE Albuquerque Field Office, November, 1992.

4 Parker O-ring handbook, Parker Seal Group, O-Ring Division, 2360 Palumbo Drive, P.O. Box 11751, Lexington, KY 40512, September, 1992. 
Appendix A-Pressure Calculations 


\section{Sandia National Laboratories}

date: $3 / 10 / 93$

Abuquerque, New Mexico 87185

to: A. R. York, 5165

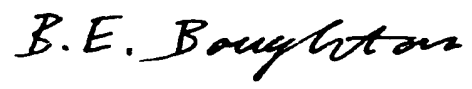

from: B. E. Boughton, 5165

subject: Review of Pressure Vessel Calculations

I have reviewed your pressure vessel calculations for the Generic Accident-resistant Package containment vessels T3 and T4 using the ASME Boiler and Pressure Vessel Code as you requested. Since I used a wider design temperature range, the maximum pressures are slightly more conservative than your computation. Taking this into account, your speadsheet appears to give the correct final maximum pressures.

BEB:5165

Attachment:

Pressure Vessel Calculations (Review) spreadsheet generated independently from A. R. York

Copy to:

J.M. Freedman, 5165

R.S. Pacheco, 5165 
PRESSURE VESSEL CALCULATIONS (Review)

(ASME Boiler and Pressure Vessel Code)

\section{Design Parameters}

\begin{tabular}{|r|lc|}
\hline 1 & Material & $304 \mathrm{~L}$ SS \\
\hline 2 & Young's Modulus (psi) & $2.90 \mathrm{E}+07$ \\
\hline 3 & Wall thickness (in) & 0.188 \\
\hline 4 & Cylinder I.D. (in) & 13.624 \\
\hline 5 & Cylinder inside radius (in) & 6.812 \\
\hline 6 & Cylinder O.D. (in) & 14.000 \\
\hline 7 & Length (in) & 60.625 \\
\hline 8 & Weld efficiency & 1.000 \\
\hline 9 & Design temperature (F) & $(-20$ to 650) \\
\hline
\end{tabular}

\begin{tabular}{|r|c|c|}
\hline & $\begin{array}{c}\text { Max Stress } \\
\text { (psi) }\end{array}$ & $\begin{array}{c}\text { Allowable } \\
\text { Stress } \\
\text { (psi) }\end{array}$ \\
\hline Int. & 432 & 15900 \\
\hline Ext. & 81 & 7500 \\
\hline
\end{tabular}

Maximum Allowable Stress (UG-23)

\begin{tabular}{|r|lc|}
\hline 1 & $\begin{array}{l}\text { Max tensile stress from Table UHA- } \\
23 \text { (psi) }\end{array}$ & 15900 \\
\hline & $\begin{array}{l}\text { Max longitudinal compressive } \\
\text { stress; min of 1,4,5 (psi) }\end{array}$ & 7500 \\
\hline 3 & step 1 - factor A & 0.0034 \\
\hline 4 & step 2/3 - factor B & 7500 \\
\hline 5 & step 4 - factor B & 48679 \\
\hline
\end{tabular}

Internal Pressure on Cylinder (UG-27)

\begin{tabular}{|r|ll|}
\hline 1 & Circumferential stress (psi) & 432 \\
\hline 2 & Longitudinal stress (psi) & 887 \\
\hline 3 & $\begin{array}{l}\text { Max internal pressure; min of 1,2 } \\
\text { (psi) }\end{array}$ & 432 \\
\hline
\end{tabular}

External Pressure on Cylinder (UG-28)

\begin{tabular}{|r|lc|}
\hline 1 & Total length (in) & 62.9 \\
\hline 2 & Outside diam / thickness ratio & 74.5 \\
\hline 3 & Length / outside diam ratio & 4.5 \\
\hline 4 & step 2/3 - factor A & 0.00042 \\
\hline 5 & step 4/5 - factor B & 4500 \\
\hline 6 & step 6 & 81 \\
\hline 7 & step 7 & 110 \\
\hline & $\begin{array}{l}\text { Max external pressure; min of 6,7 } \\
\text { (psi) }\end{array}$ & $\mathbf{8 1}$ \\
\hline
\end{tabular}

Internal Pressure on Ellipsoidal Head (UG-32)

\begin{tabular}{|r|ll|}
\hline 1 & Max internal pressure (psi) & 438 \\
\hline
\end{tabular}

External Pressure on Ellipsoidal Head (UG-33)

\begin{tabular}{|r|lc|}
\hline 1 & Major / minor axis ratio & 2.0 \\
\hline 2 & Factor Ko, Table UG-33.1 & 0.9 \\
\hline 3 & Ro & 12.6 \\
\hline 4 & step 1 - factor A & 0.0019 \\
\hline 5 & step 2/3 - factor B & 7000 \\
\hline 6 & step 4 & 104 \\
\hline 7 & step 5 & 404 \\
\hline & $\begin{array}{l}\text { Max external pressure; } \text { min of 6,7 } \\
8\end{array}$ & 104 \\
\hline
\end{tabular}




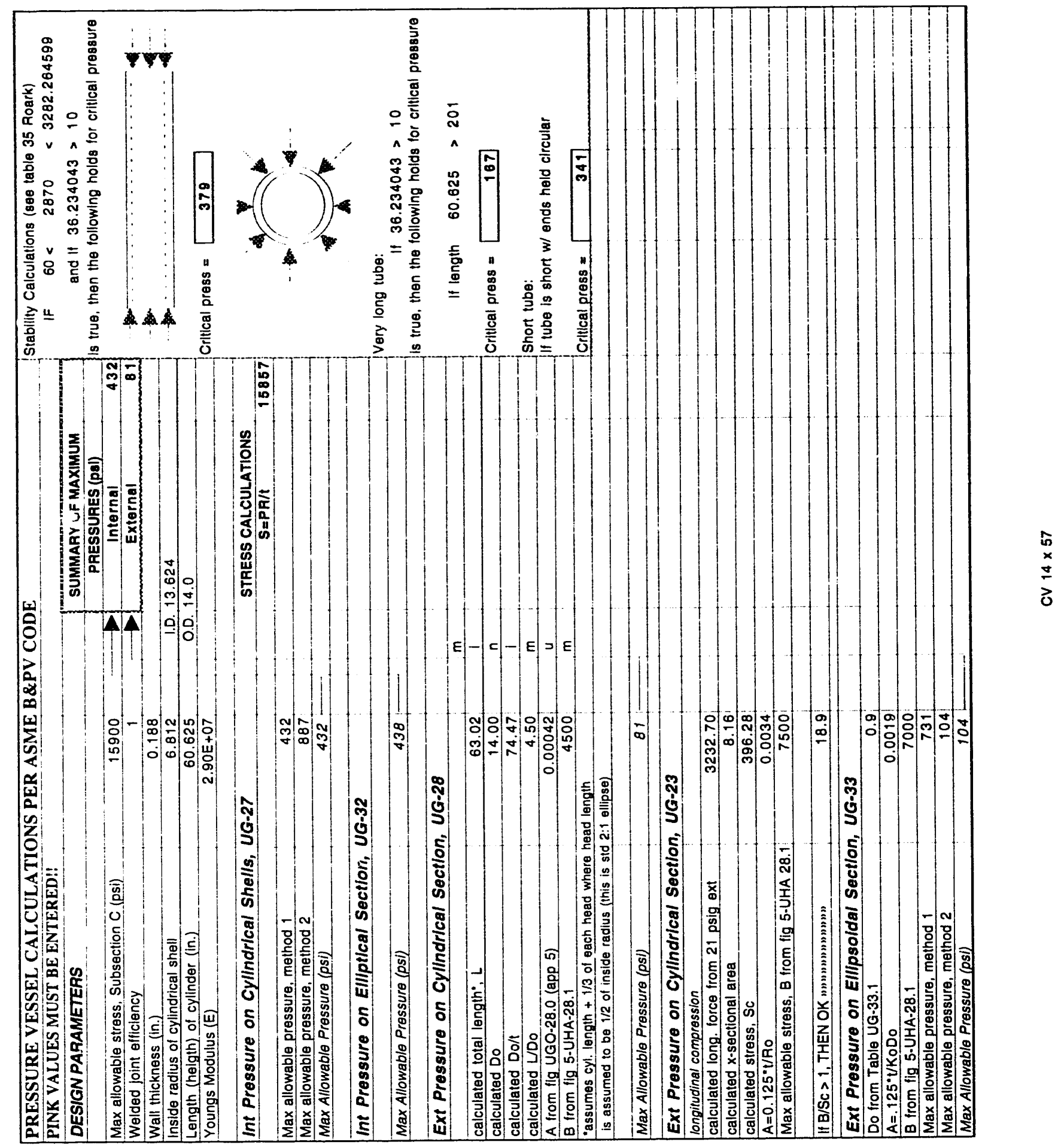




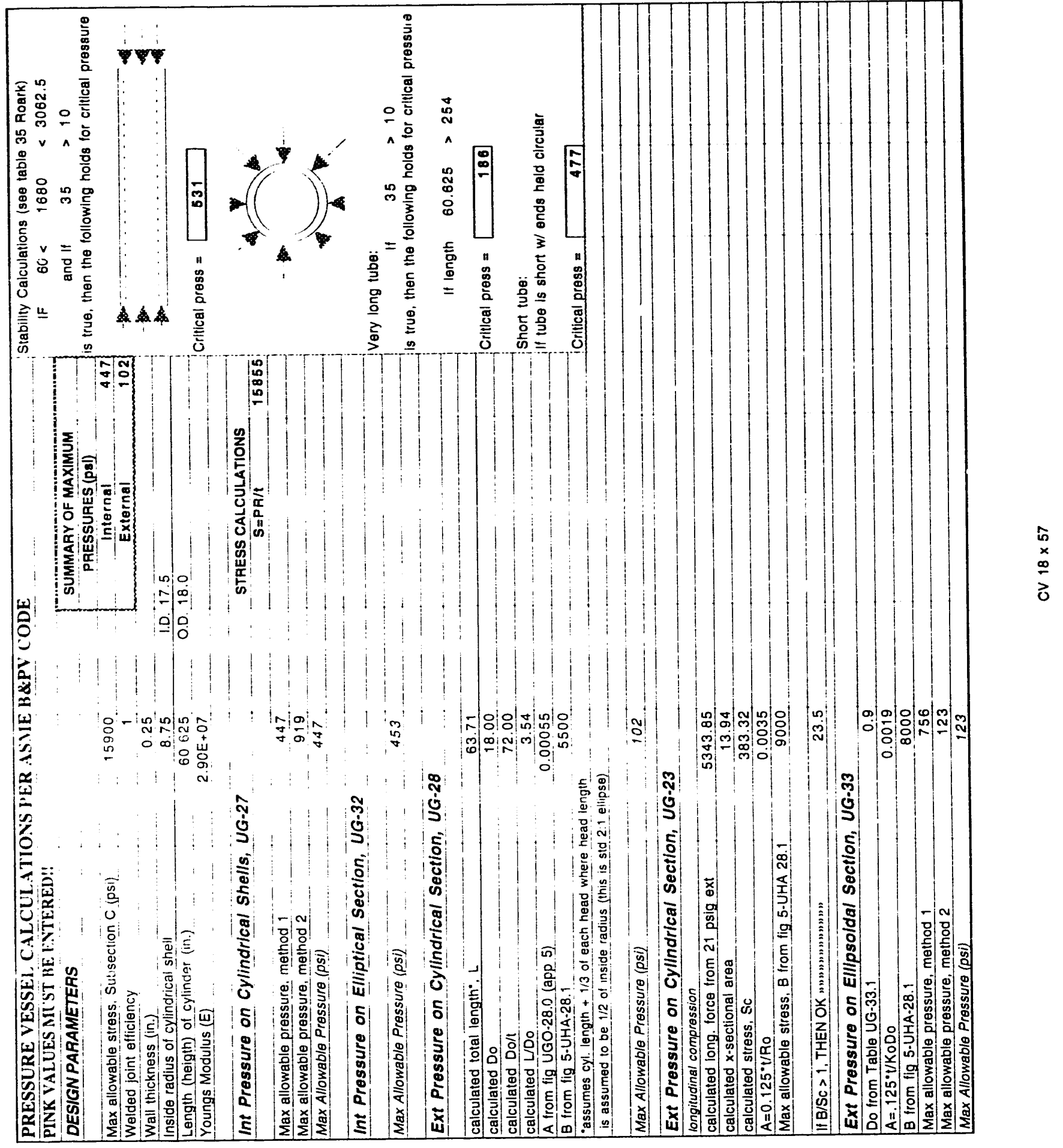




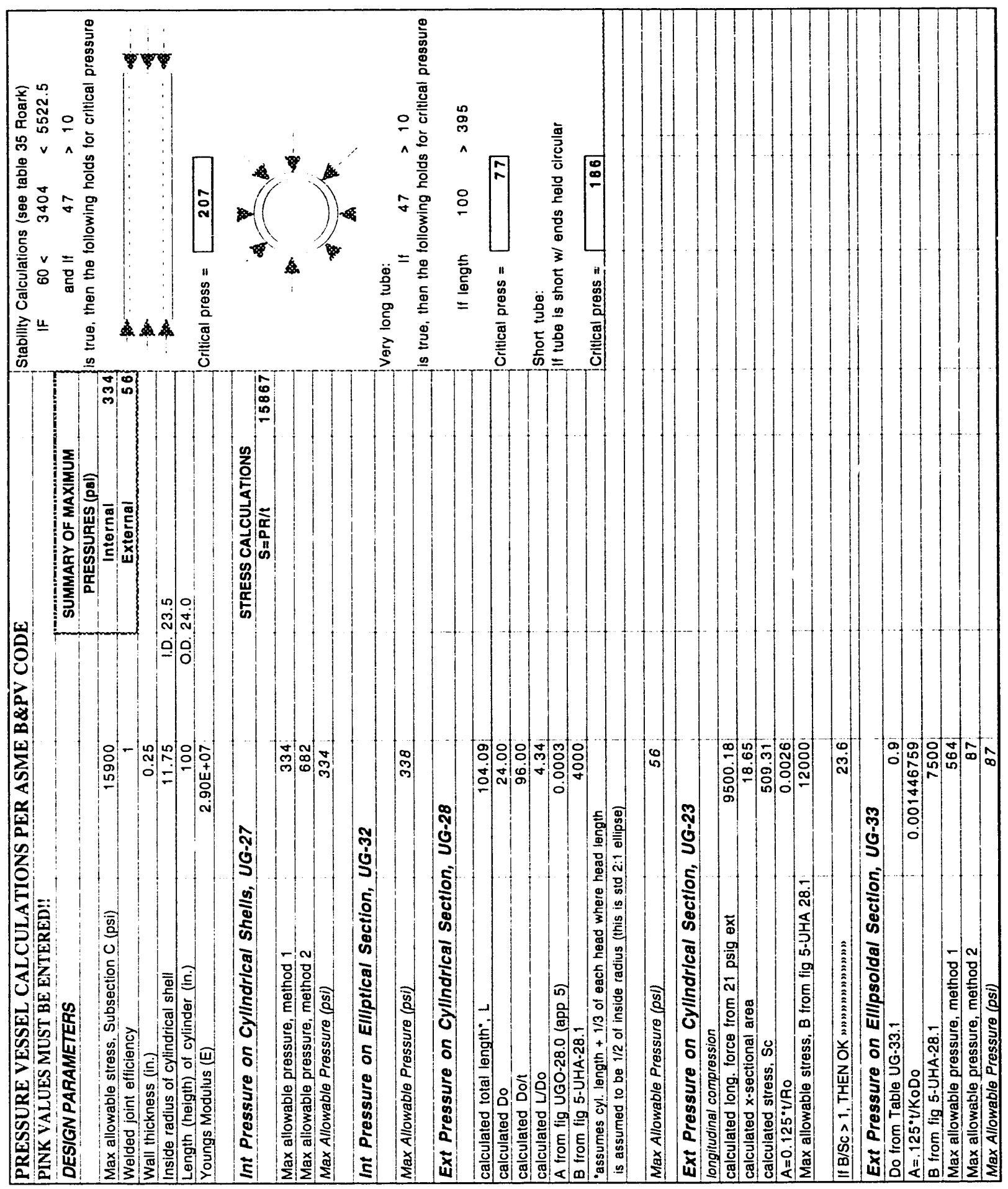




\section{Sandia National Laboratories}

date: August 6, 1993

Albuquerque, New Mexico 87185

to: Dale Hill, Org. 5165

$$
\text { Manlow sinwits }
$$

from: Marlene Shields, Org 2742

subject: Pressure Vessel Proof Tests

Three containment vessels were tested in the Force and Pressure Lab. Two of these were tested in the Area I Lab located in Building 860. Due to the size of the third vessel the test was conducted in AIII, Building 6730. Testing was conducted during the week of June 8, 1993. The following table summarizes the test conditions for each vessel.

VESSEL ID PROOF PRESSURE HOLD TIME

$\begin{array}{llll}\text { T3 } 14^{\prime \prime} \text { Dia. } & 185 \text { psig } & 3 \mathrm{~min} . & \text { Pass } \\ \text { T4 18" Dia. } & 115 \text { psig } & 3 \mathrm{~min} . & \text { Pass } \\ \text { S7 24" Dia. } & 170 \text { psig } & 3 \mathrm{~min} . & \text { Pass }\end{array}$

The data gathered consisted of an $\mathbf{x}-\mathbf{y}$ recorder which plotted pressure vs. time for each of the tests. No damage to the vessels was observed upon a visual post-test inspection.

Copy to:

2742 R. A. May

2742 Test File 
Appendix B-Containment Vessel

Fabrication Drawings 


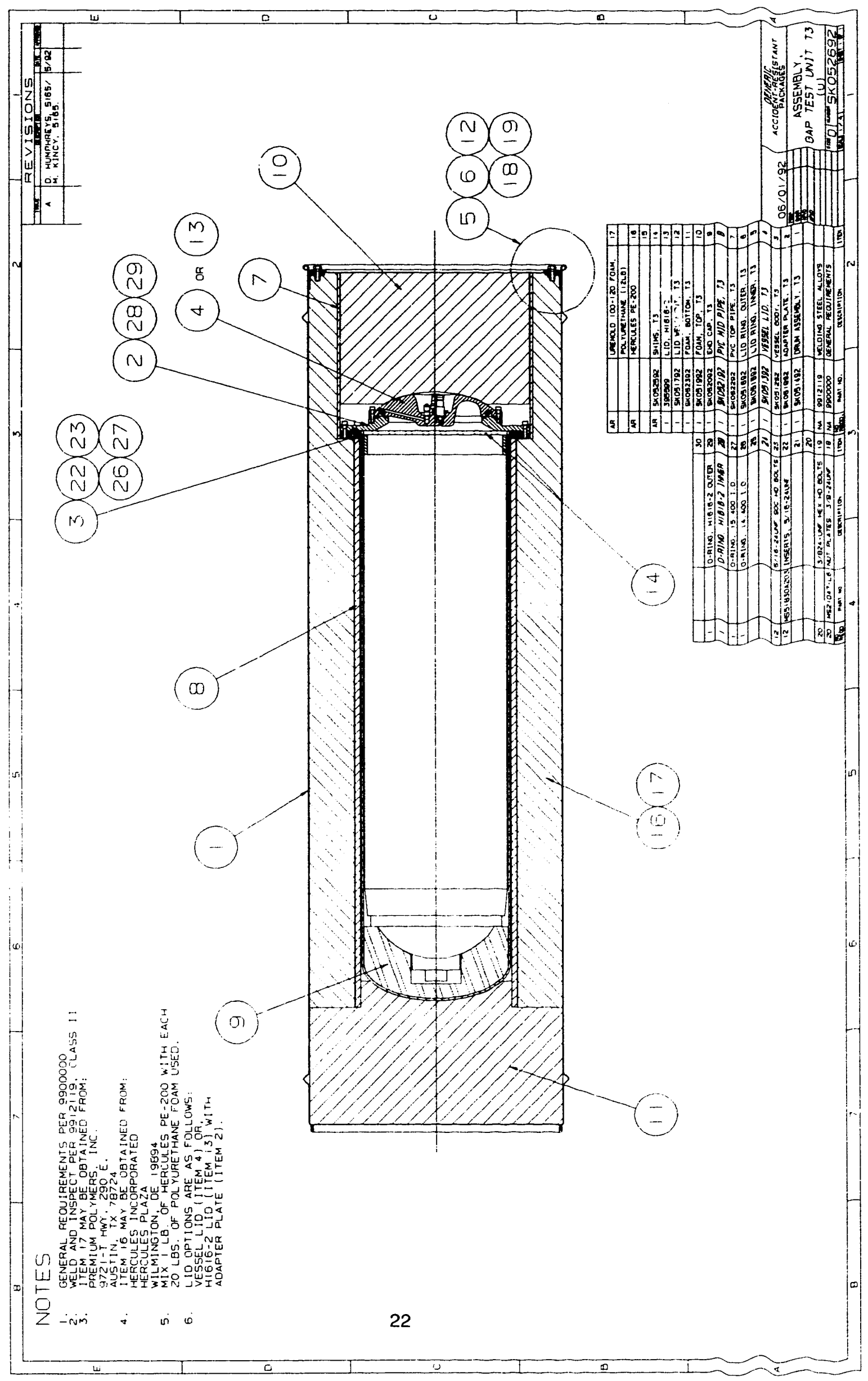




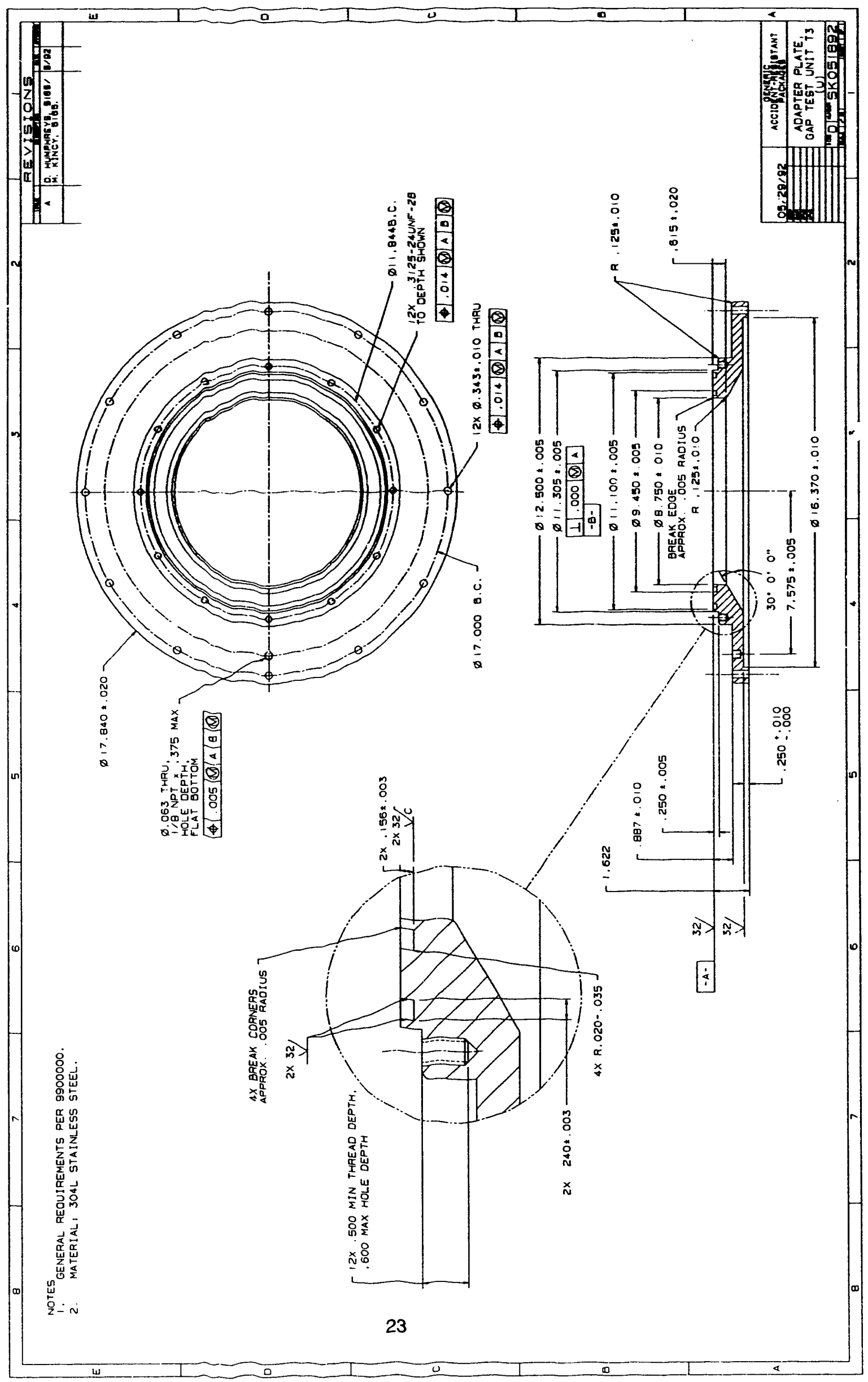




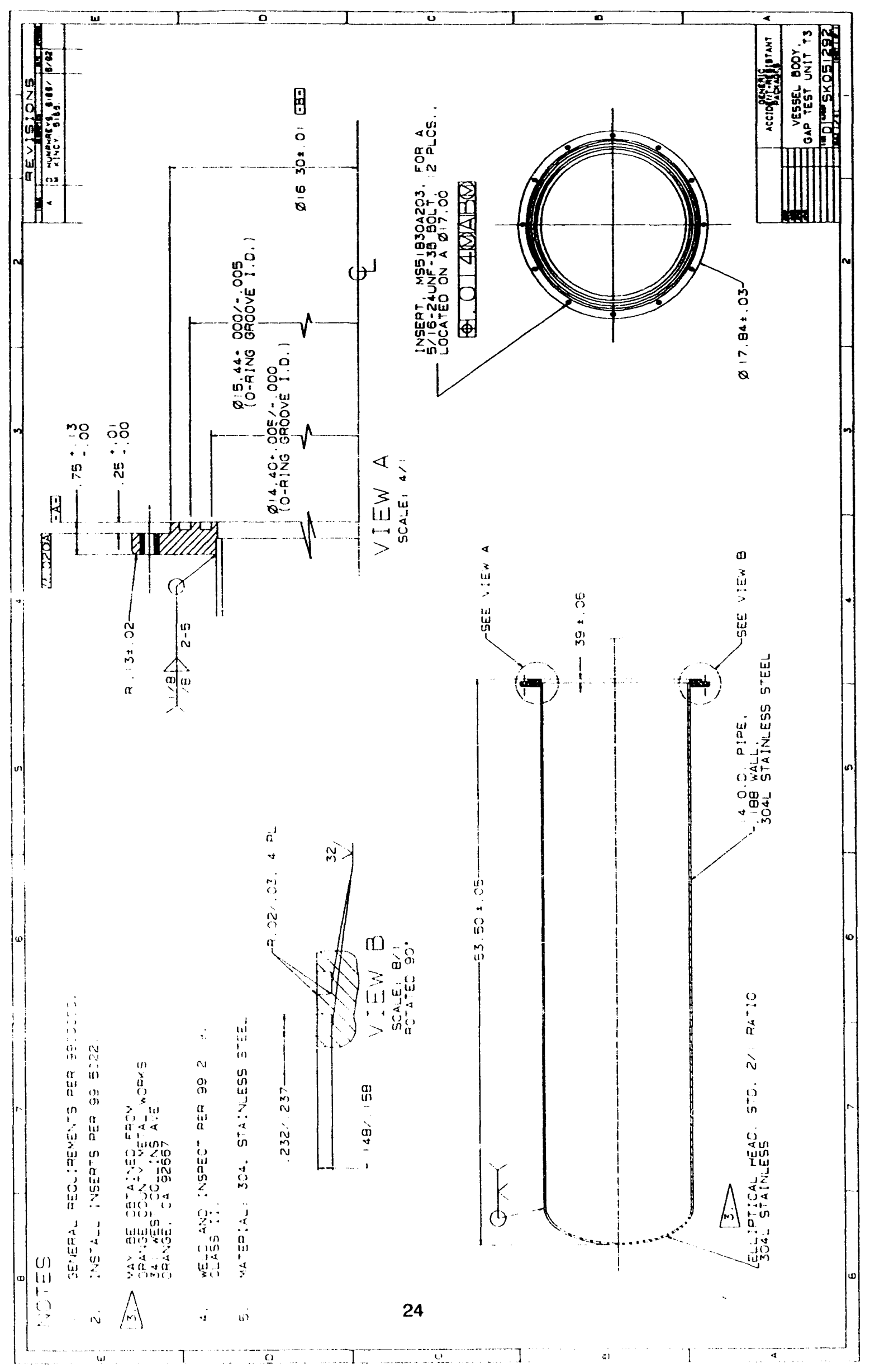




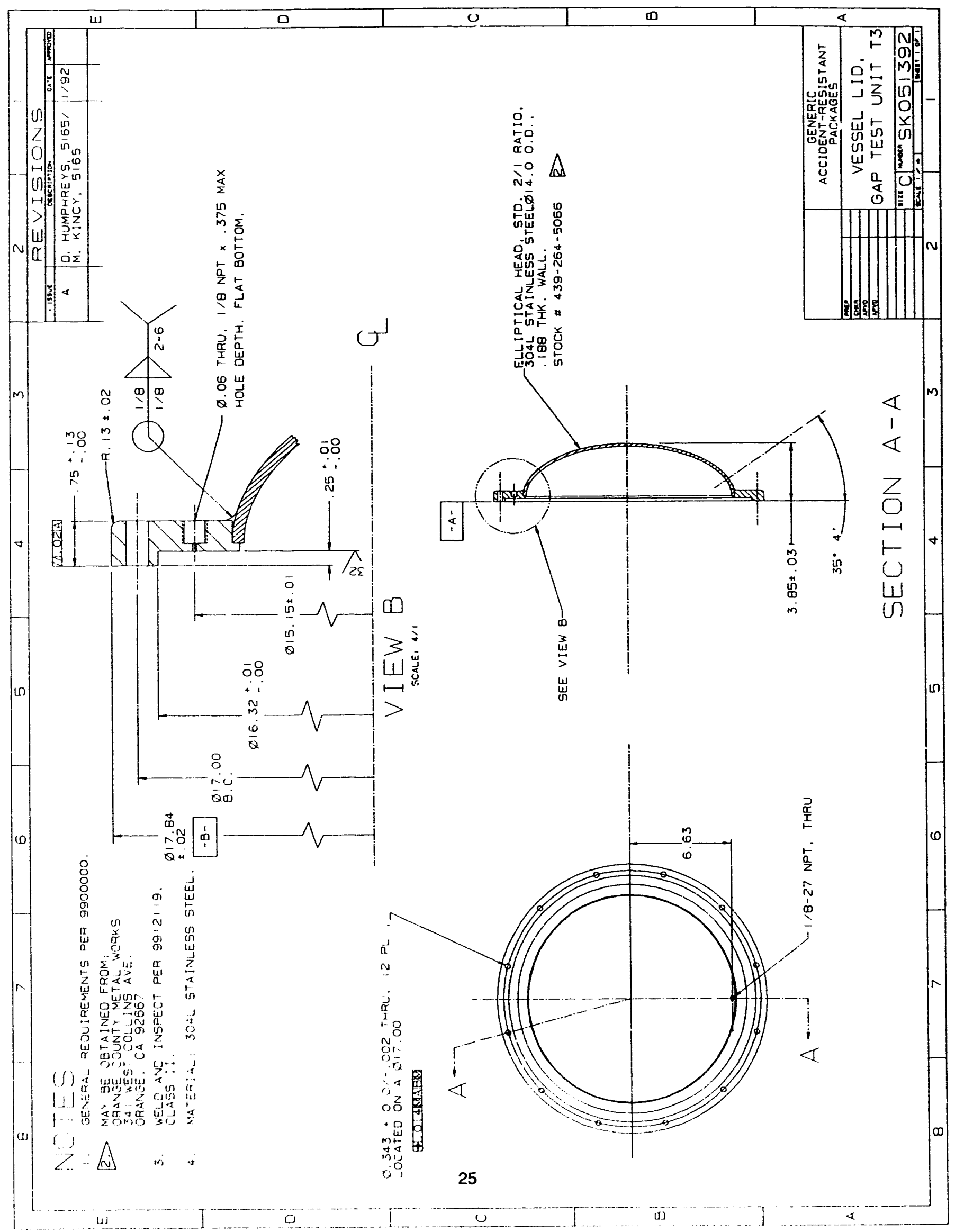




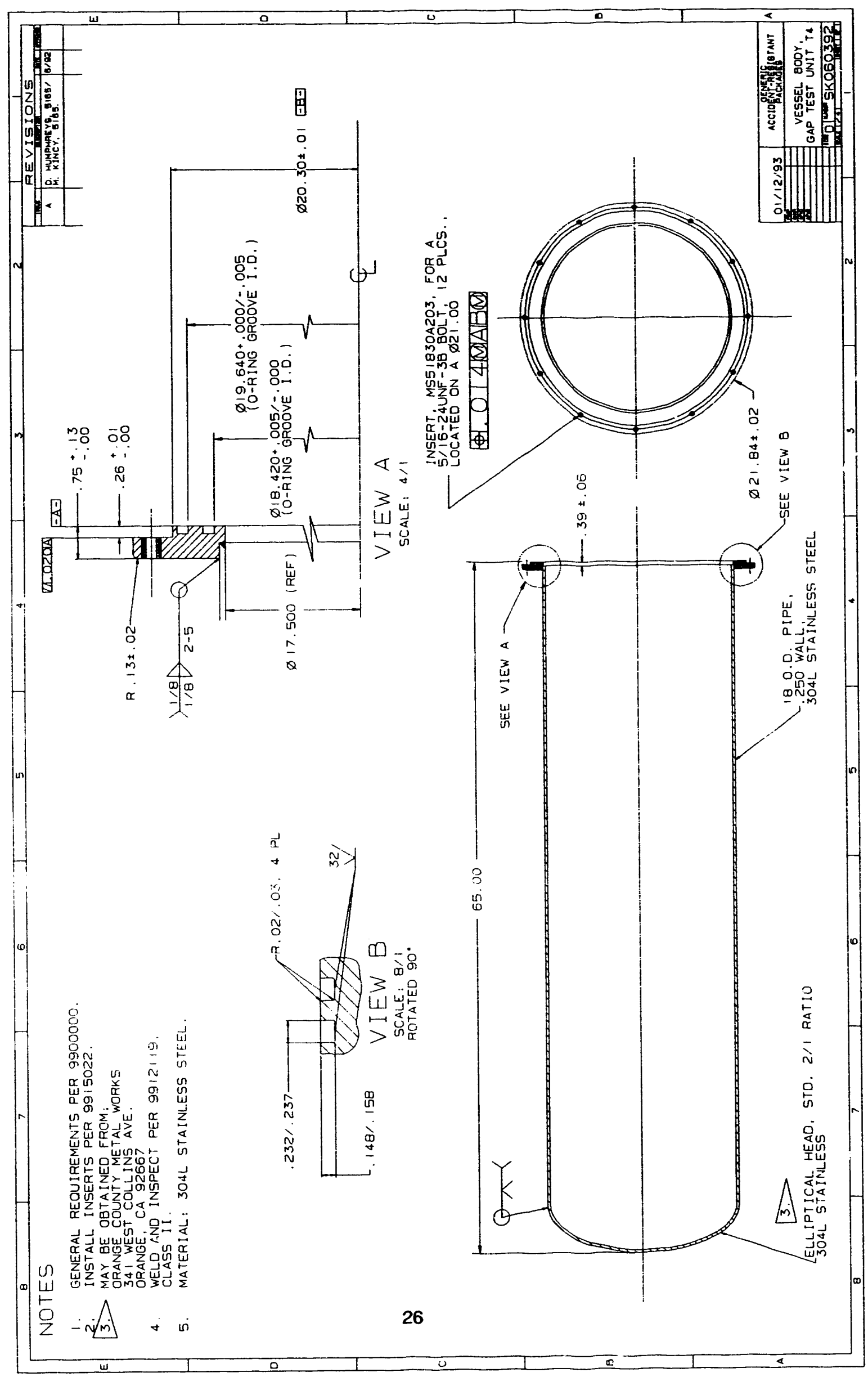




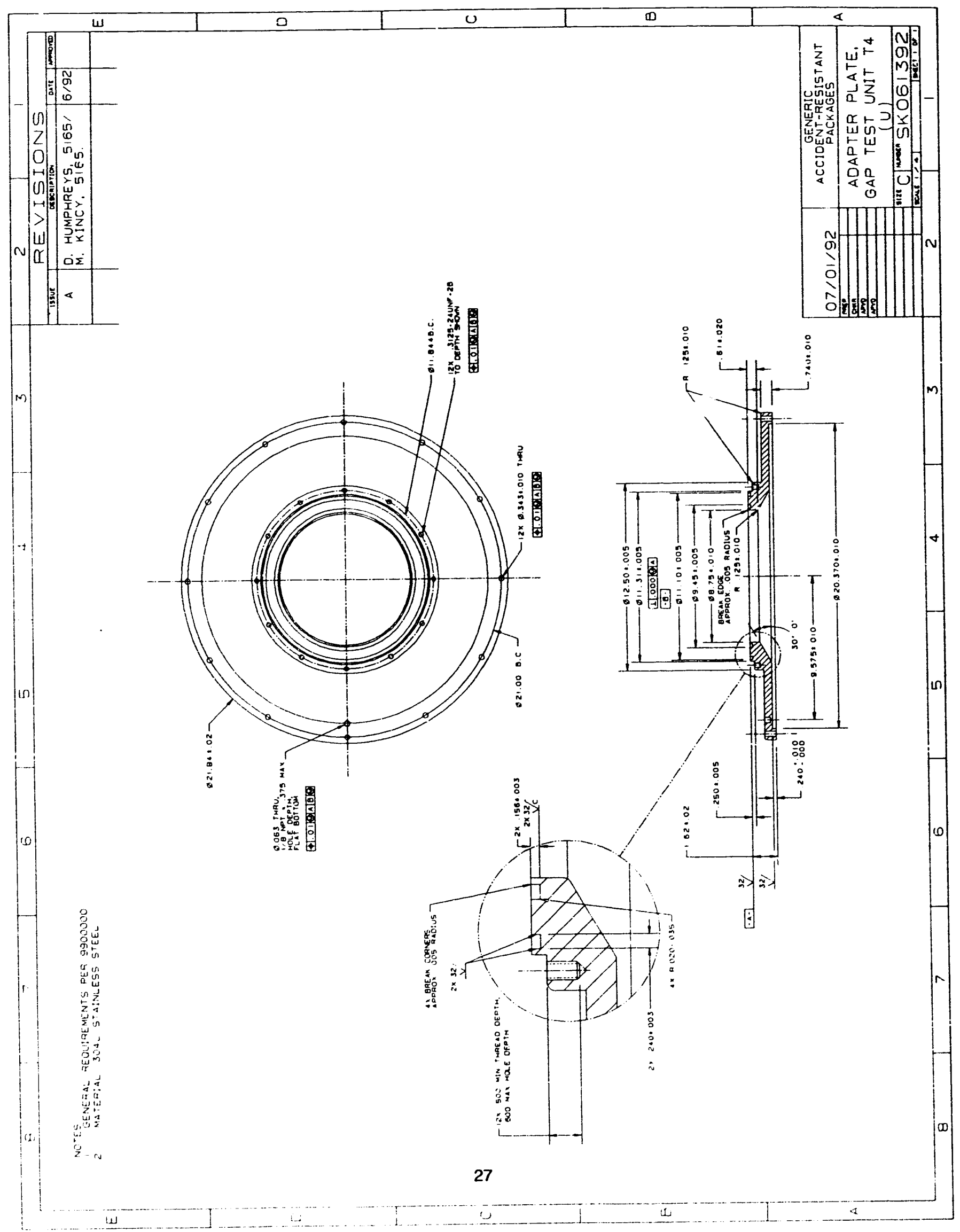




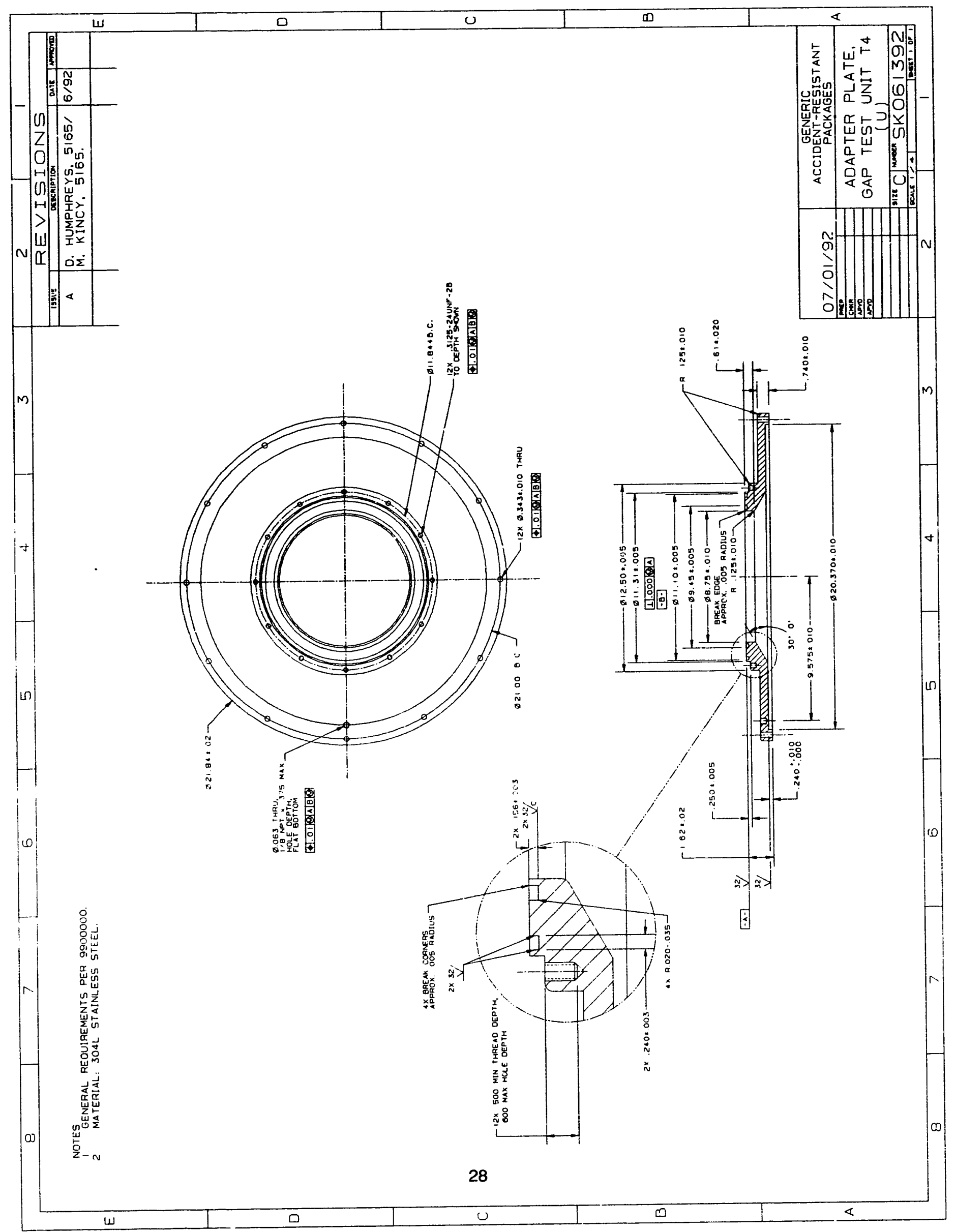




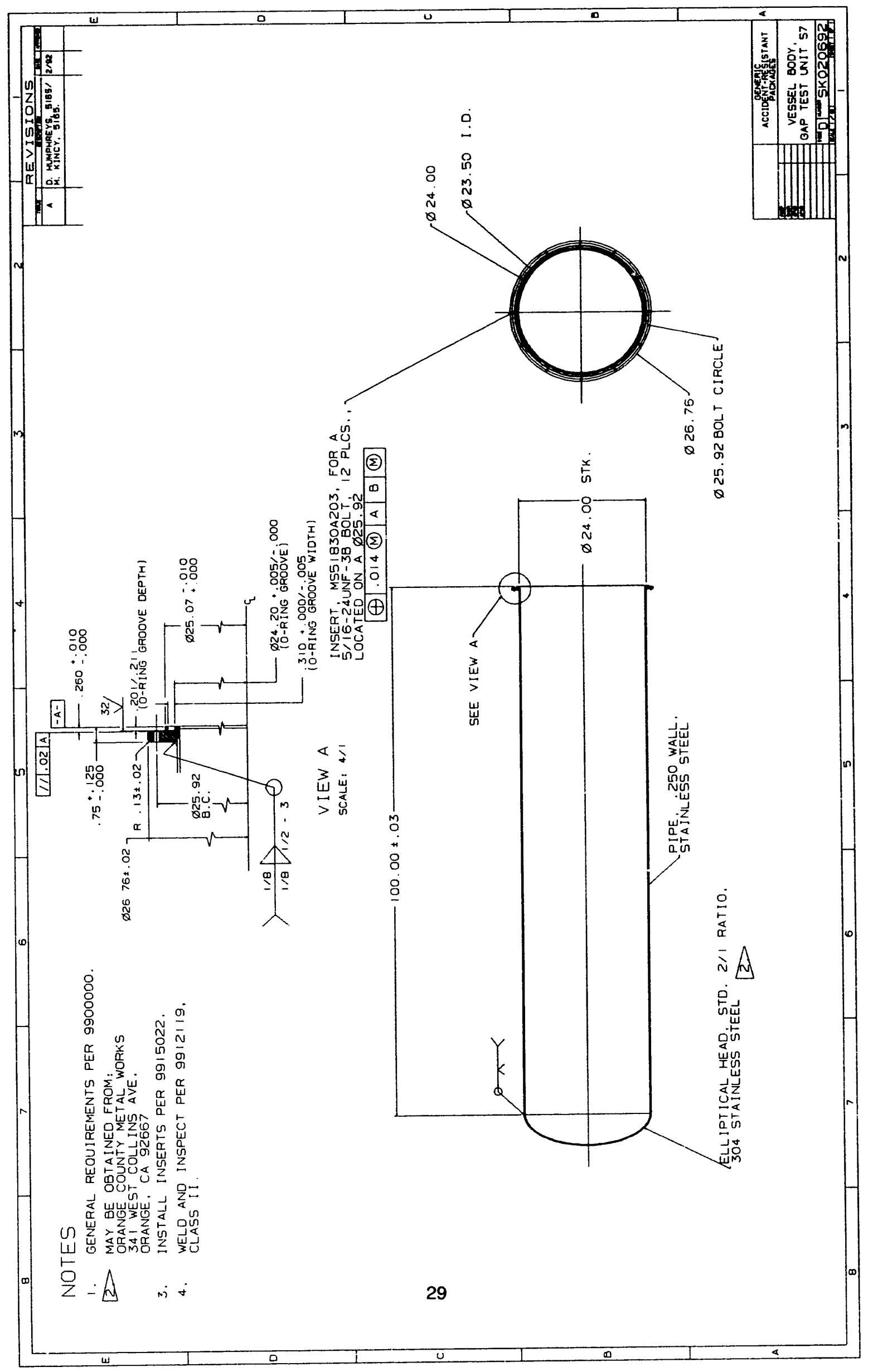




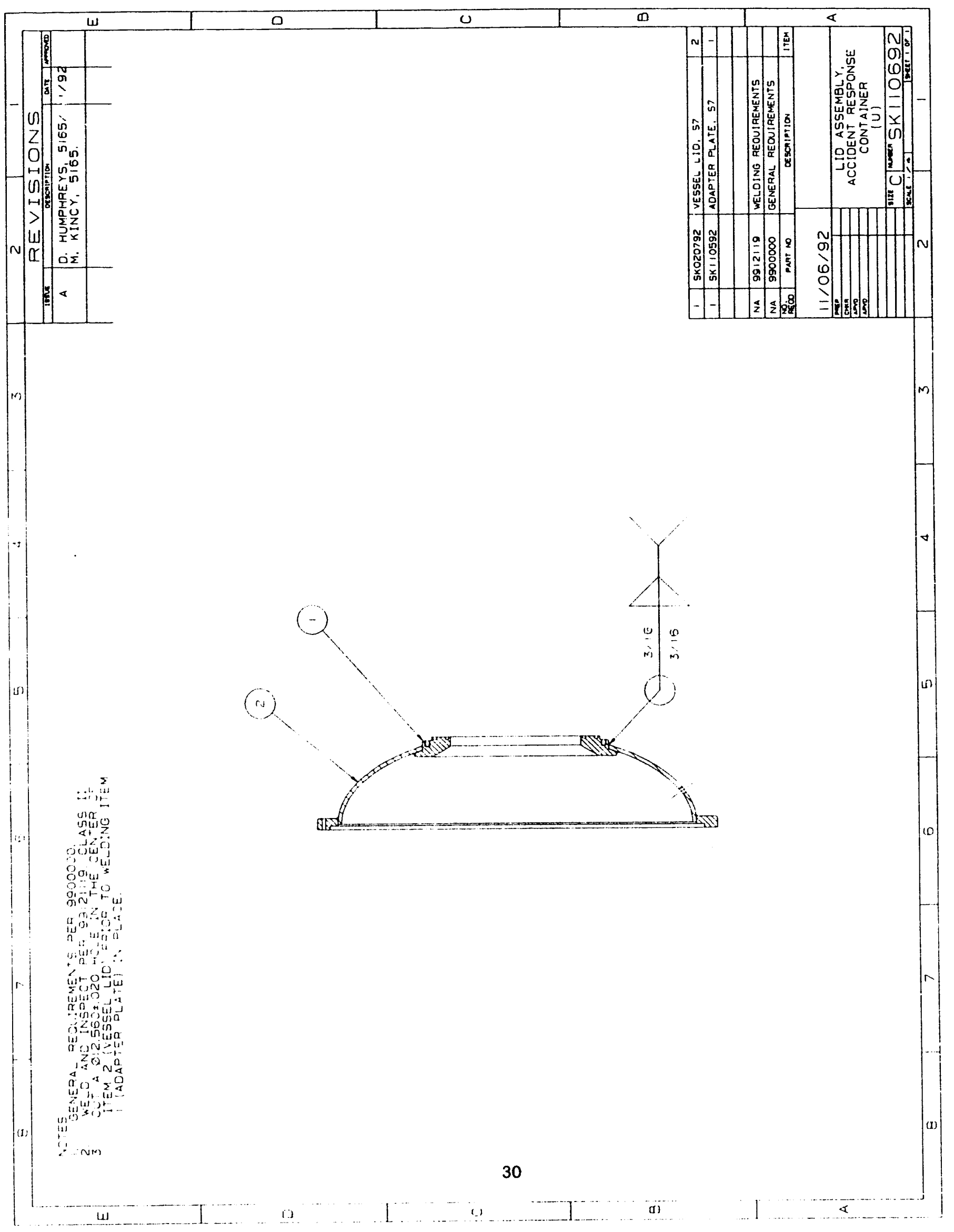




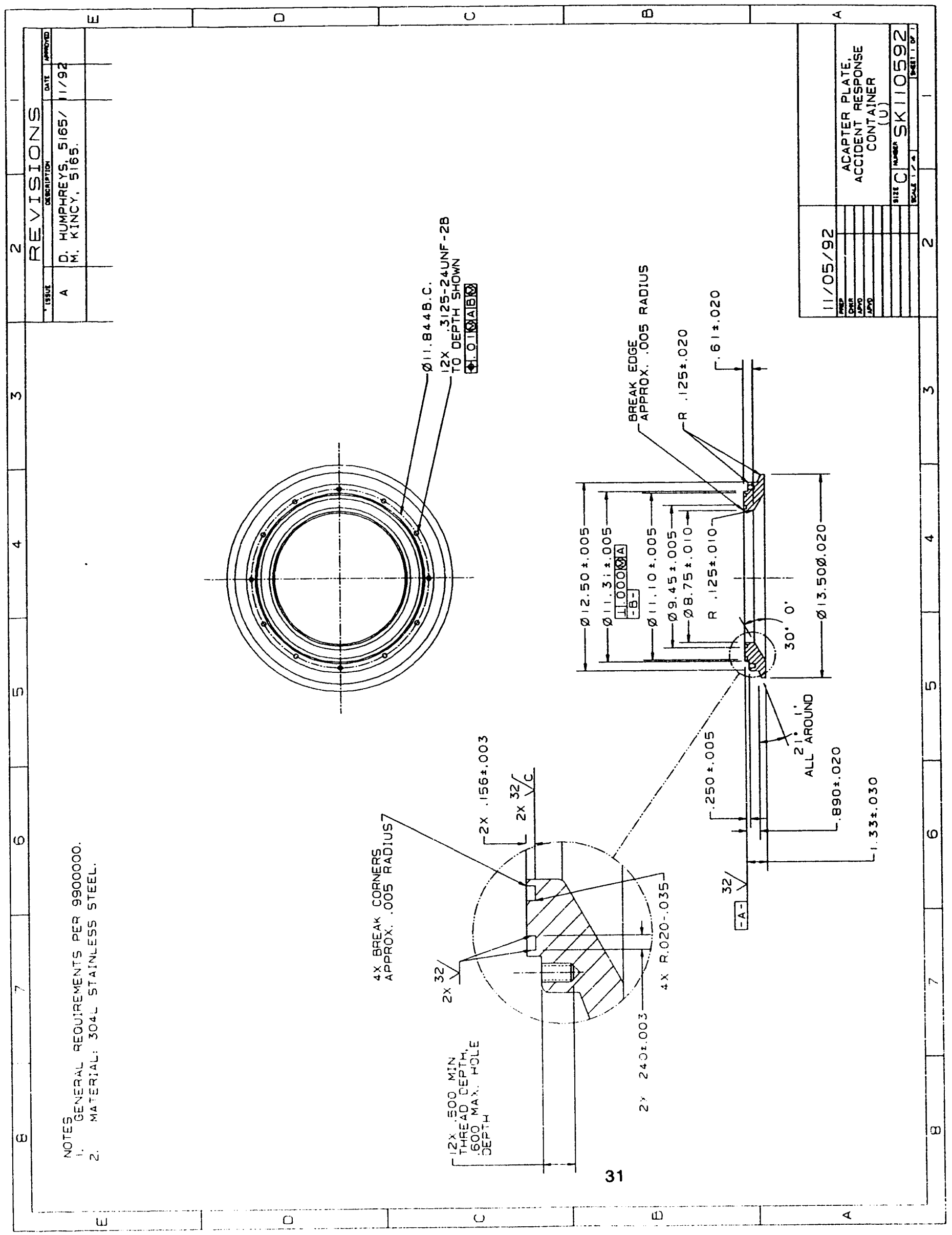




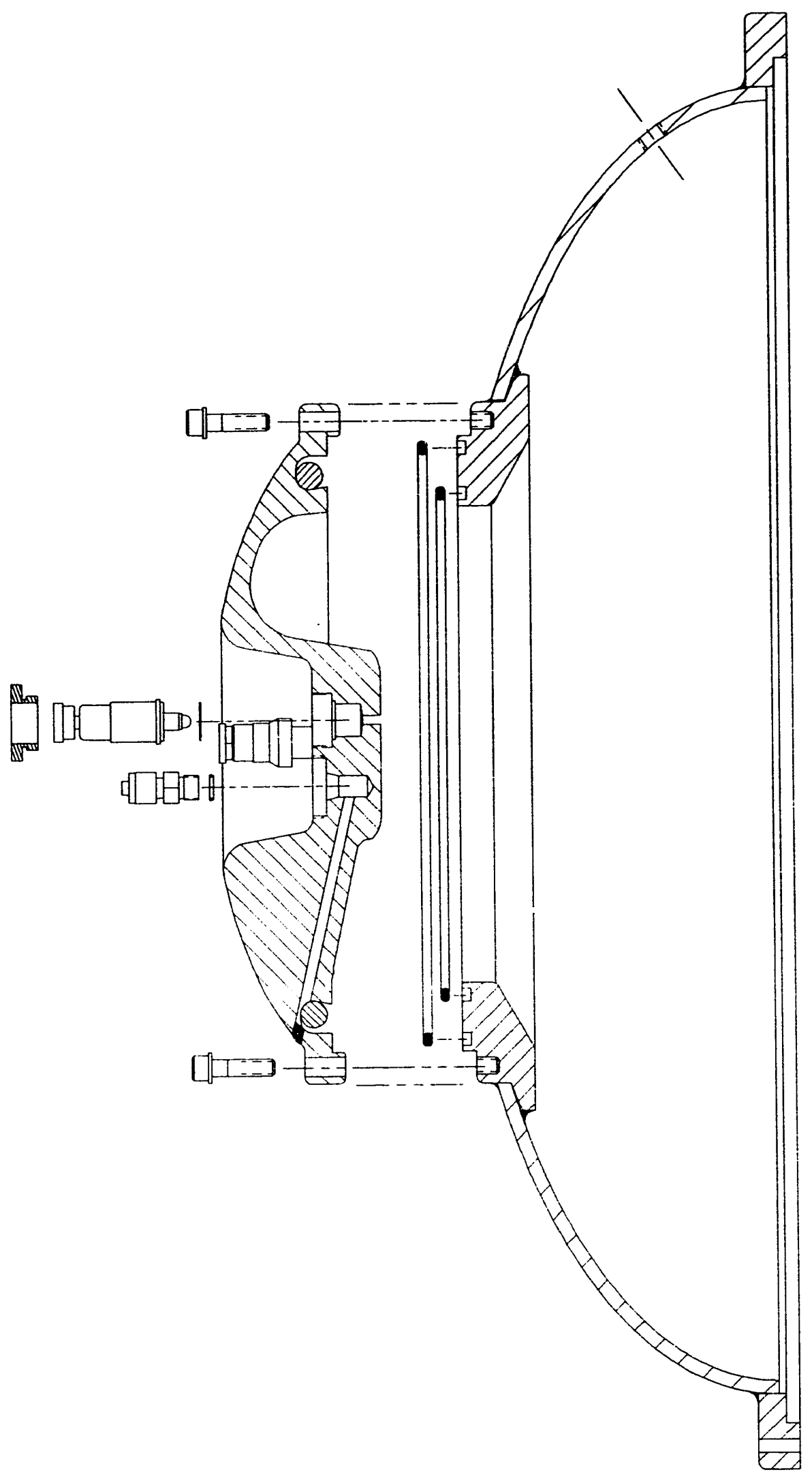


Appendix C-Impact Analyses and Other Data 


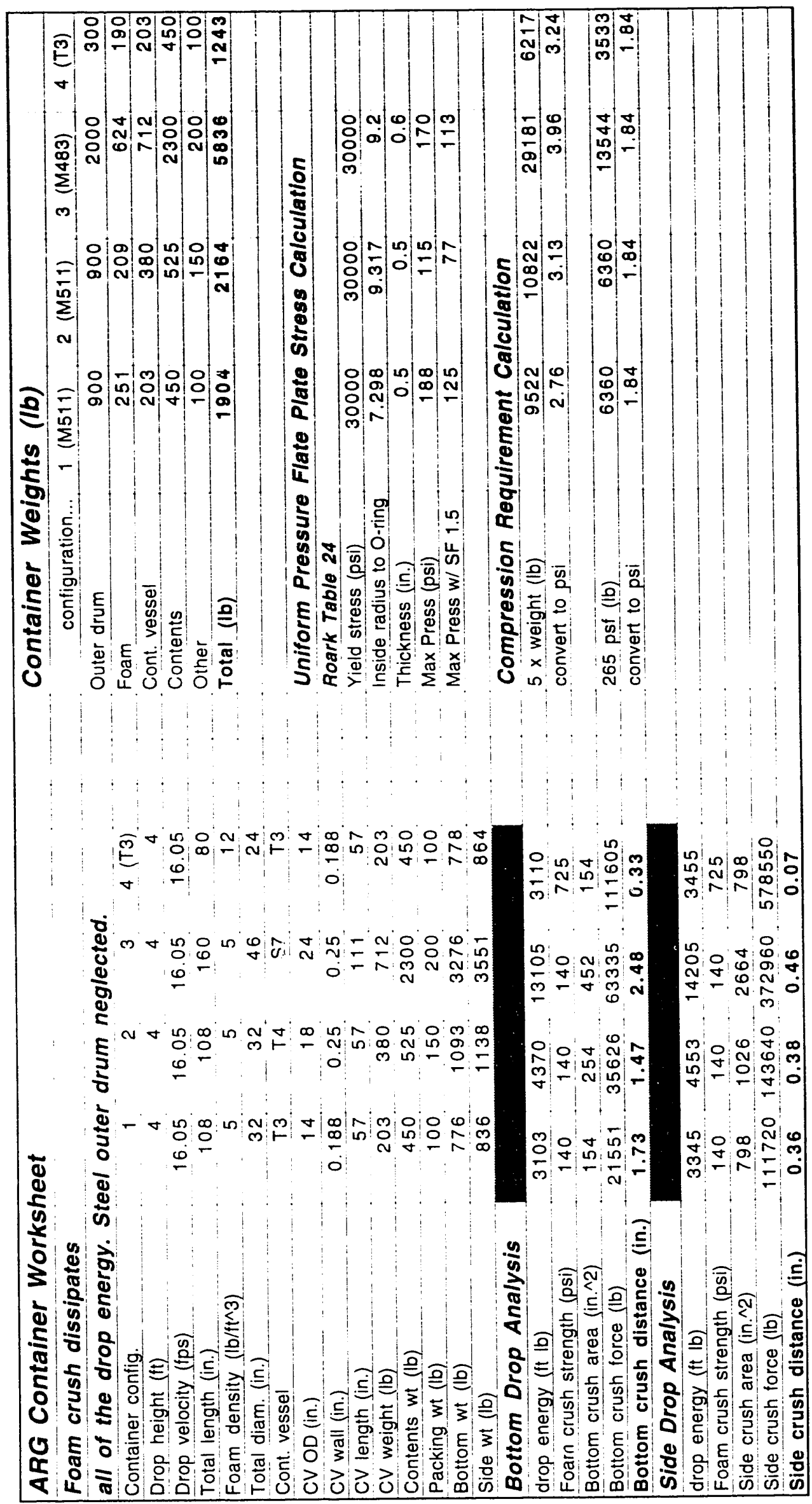


Appendix D-Memo from M.A. Kincy on Weapon Recovery Containers

35 


\section{Sandia National Laboratories \\ Abuquerque, Now Medico 87185}

date: March 29, 1993

to: Distribution

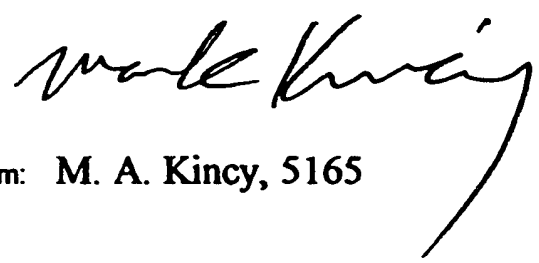

subject: Evaluation of M483 and M511 Containers for Weapon Recovery

This is a summary of analyses and tests to predict the performance of current weapon accident response containers in severe environments. Some suggestions are made for modifications to improve the performance of the containers.

\section{Container Descriptions}

The M511 and M483 containers were designed for shipping Army missile sections. Normal environment protection was specifically tuned for these missiles. Accident protection was not a requirement for the original container applications. Modifications to these containers will enhance their performance for weapon recovery applications, both for normal and abnormal environments, but the performance in accidents will not approach that of containers designed for accident protection.

Both containers are similar in construction, with a mild steel cylindrical shell and a "clamshell" closure configuration secured with bolts. A welded base with lifting pockets for fork lift access is part of each. Major dimensions are listed below.

$\begin{array}{lcc} & \mathbf{M 4 8 3} & \text { M511 } \\ \text { Overall Length, inches } & 168 & 116 \\ \text { Overall Width, inches } & 52 & 36 \\ \text { Overall Height, inches } & 55 & 39 \\ \text { Inside Diameter, inches } & 46 & 32 \\ \text { Inside Length, inches } & 160 & 108 \\ \text { Wall Thickness, inches } & .075 & .075 \\ \text { Material } & \text { low carbon steel } & \text { low carbon steel } \\ \text { Number of Closure Bolts } & 28 & 22\end{array}$




\section{Performance Calculations and Test Results}

\section{Impact Analysis}

The 483 container is larger and will suffer more damage in impact testing than the M511. For a 30 foot drop of the heaviest M483 container configuration, a $5 \mathrm{lb} / \mathrm{cu} \mathrm{ft}$ polyurethane foam will have sufficient energy absorption to protect the payload. The M483 container with a B83 center case mockup and a 24 inch diameter containment vessel will have a gross weight exceeding $6000 \mathrm{lb}$. In drops from 30 feet on an unyielding target, the outer shell should deform up to 5 inches on a side impact and 10 inches in an end impact. For the M511 container with $5 \mathrm{lb} / \mathrm{cu} \mathrm{ft}$ foam and an 18 inch diameter by 72 inch long payload and a gross weight of $2200 \mathrm{lbs}$, the outer shell should deform up to 4 inches on a side impact and 8 inches in an end impact. Worst case impact orientations for the steel outer structure should be center of gravity over the impacting corner or slapdown with the container angled approximately 20 degrees from horizontal at impact. These orientations concentrate loads in the corners of the structure.

\section{Transportation Loads Analysis}

Tiedown loads of $10 \mathrm{~g}$ forward, $5 \mathrm{~g}$ vertical, and $2 \mathrm{~g}$ lateral are commonly used to qualify container tiedown systems for aircraft transport. Response of the container foam to these loads is calculated here. The crush strength of $5 \mathrm{lb} / \mathrm{cu} \mathrm{ft}$ polyurethane foam is approximately $100 \mathrm{psi}$. The crush strength of the field-installed $1.75 \mathrm{lb} / \mathrm{cu} \mathrm{ft}$ foam should be approximately $40 \mathrm{psi}$. The smallest area and highest loads occur in the forward direction. The foam stresses calculated for some representative payload configurations subject to $10 \mathrm{~g}$ are presented below.

$\begin{array}{ccc}\text { payload diameter, in. } & \text { payload weight, lb } & \text { foam stress, psi } \\ 8 & 500 & 100 \\ 12 & 1000 & 88 \\ 18 & 2000 & 78 \\ 24 & 3500 & 77\end{array}$

Small, dense payloads produce the highest foam loads. Although these loads may cause some yielding of the foam inside the container, they will not cause significant deformation of the outer container. This should be acceptable since $10 \mathrm{~g}$ represents an abnormal flight environment. Because the ends of the container will be loaded most severely, use of the higher density foams on the ends is beneficial.

\section{Puncture Response Analysis}

Puncture testing of Type B containers is part of accident qualification. Containers are dropped from 40 inches onto a 6 inch diameter steel puncture bar. Empirical formulas were used to predict the performance of the containers to these puncture loads. The M483 will again be the limitin' case, because of its greater weight. A $5000 \mathrm{lb}$ gross weight M483 will have 200,000 inch pounds of drop energy in a puncture test, and only 24,000 to 65,000 inch pounds are predicted to puncture the shell. The heaviest container configurations would certainly penetrate the outer shell. This may still be acceptable in a subsequent fire, if a fire retardant foam is used. Either the M483 or M511 with the .075 inch steel shell would have to weigh less than $1500 \mathrm{lb}$ to not penetrate the outer shell in a Type B puncture test. 
Fire Response Analysis

Based on comparison to tests of other containers using fire retardant foam, the temperature of the payload inside either the M483 or M511 should remain well below $300^{\circ} \mathrm{F}$ in a Type B 30 minute fire. For comparison, a 71 minute jet fuel fire on a foam insulated container 16 inches in diameter and 44 inches long caused an internal temperature peak of $360^{\circ} \mathrm{F}$. This was an optimal configuration with no mechanical damage prior to the burn and a thermal barrier outside the foam. Elastomeric seals in a containment vessel can survive up to $600^{\circ} \mathrm{F}$ for short durations. However, fire response of containers using foam is dependent on the internal convection paths and the iniegrity of the outer shell and the type of foam. A fire retardant foam developed for containers performs much better than most standard foams.

\section{Drop Test of M483 based ARG Container}

On September 30, 1992, a container based on the M483 was drop tested at the Sandia cable test site. The container had a mockup representing a B-83 center case in a 24 inch diameter containment vessel and $5 \mathrm{lb} / \mathrm{cu}$ ft foam. The container was dropped from 30 feet onto the unyielding target at the facility. The container was oriented with the center of gravity over the impacting corner. The test configuration is shown below

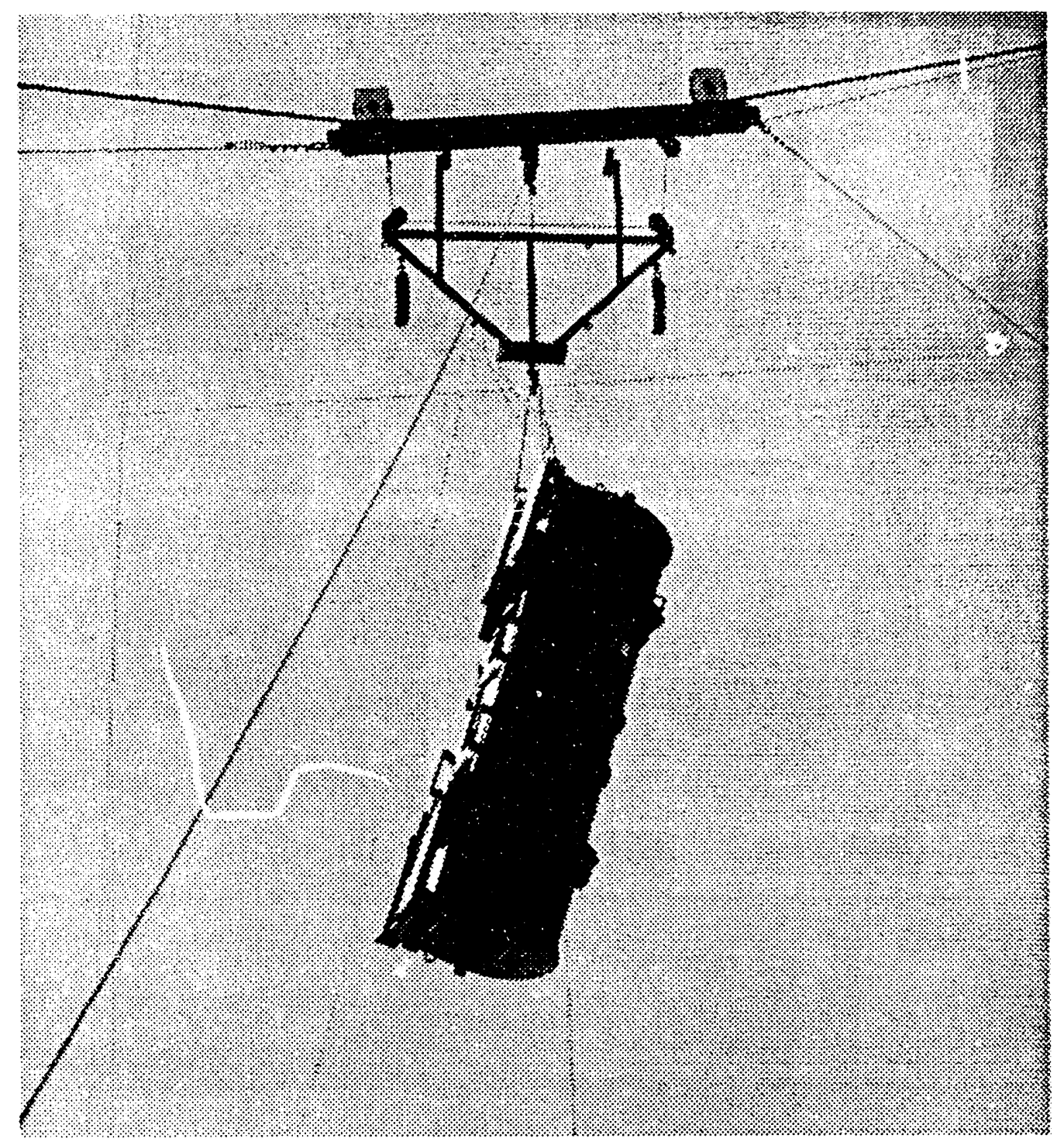



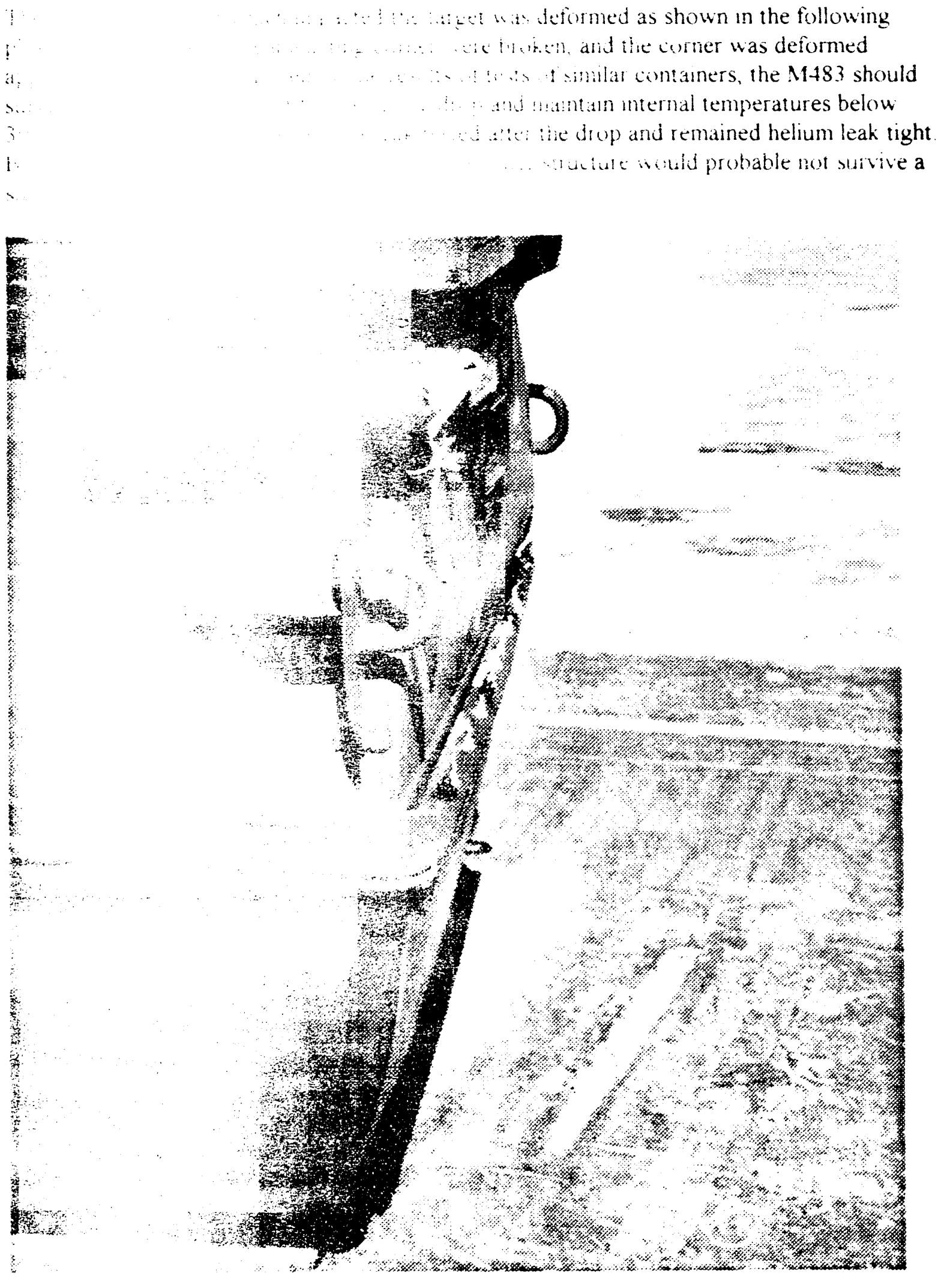

5165 A R York

5105 D 1. Humphreys

1072.11 a kincy 
The M483 container is shown below, the M511 is similar.

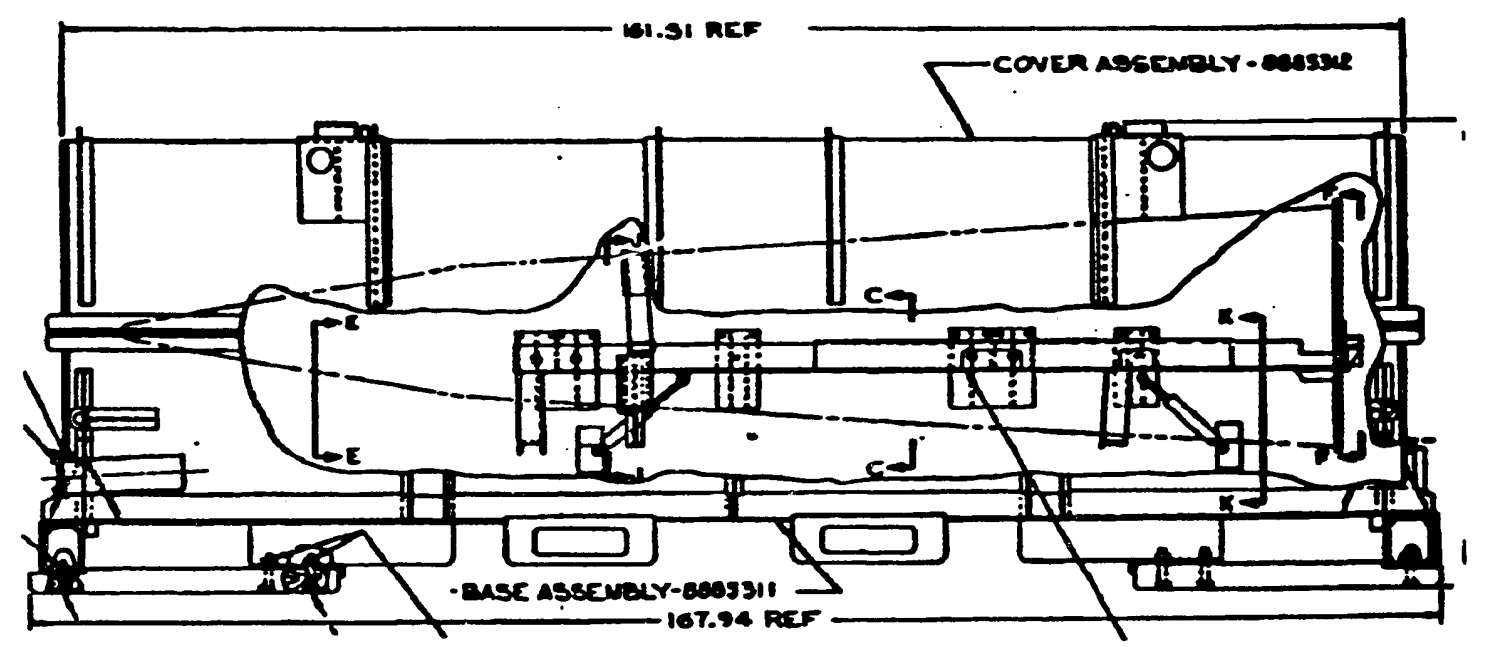

\section{Suggested Modifications}

The following modifications for improved performance are based on other container designs.

\section{Lid Bolts}

The lid closures on both containers are weak compared to the rest of the structure. A balanced configuration for the lid attachment will require $3 / 8$ inch diameter bolts spaced approximately 4-6 inches apart around the flange. This will make the flange strength closer to the strength of the shell. Similar bolt spacing is appropriate for both containers.

\section{Foam Supports}

Rigid polyurethane foam can provide significant impact and fire protection for the container contents and could be cut to size in field operations to package different payloads. Use of a well characterized foam between the weapon and the outer shell of the container will assure predictable container performance. Foam with a density of $5 \mathrm{lb} / \mathrm{cu} \mathrm{ft}$ should be sufficient to match the strength of the outer structure. Foam currently used is 1.75 to $2.25 \mathrm{lb} / \mathrm{cu} \mathrm{ft}$ density and it is not fire retardant.

\section{Vent Holes}

Vent holes in the outer shell of the container are required to release the foam decomposition products during a fire. The holes should be approximately $3 / 8$ inch in diameter and should be located approximately one per square foot of surface area. Commercial polyethylene plugs can be inserted in the vent holes to provide a weather seal, and they will melt in the event of a fire to open the vents. 


\section{Thermal Barrier}

Use of a ceramic fiber insulation material between the outer shell of a container and the foam has been found to improve the performance of a foam insulation system. Because of the large thickness of foam in these containers, the thermal barrier may not be necessary. A determination can only be made after criteria for internal temperature limits and fire environments have been established. Ceramic fiber materials are potentially hazardous if handled due to inhalation of loose fibers. Use of a high temperature cloth-covered insulation is recommended if the thermal barrier will be exposed to the operators. The cloth reduces the release of loose fiber.

\section{Heat Dissipation System}

Internal heat generated by the warhead can create high temperatures inside the container if the warhead is completely surrounded by a large amount of insulation. Use of a band of conductive material around the heat generating section of the warhead will reduce internal temperatures by conducting the heat to a larger surface. Alternatively, leaving a convection space around the heat-generating part of the warhead can serve the same purpose. The design must be balanced to remove decay heat under normal conditions without absorbing too much external heat from a fire in an accident. The combination of a small of band of conductive material or free convection space in the insulation has been shown to function satisfactorily for weapon containers, but it may be necessary to select different heat dissipation configurations depending on the warhead.

\section{Inner Vessel}

An inner vessel around the waihead will allow application of additional stabilization measures as well as provide a verifiable containment system. Vessels can be fabricated most economically from standard pressure vessel heads and standard tubing. Austenitic stainless steel such as type 304 is most commonly used. A flange with bolts and elastomeric O-ring seals provides a closure for the vessel. Prototype containment vessels using this approach have been fabricated by Sandia for the generic weapon containers program.

\section{Operating Procedures}

Procedures and equipment for operating the container will have to be developed. Vessel backfilling and leak testing require careful operation to assure operator safety and proper container function. By comparison, certified Type B containers require leak testing at each assembly and annual testing and inspection, along with documented procedures and operator training. Operating convenience of these modified containers will not be as good as typical Type B containers.

\section{Container Qualification}

Qualification of the containers can not be complete without definition of specific performance requirements. Estimates presented here for the performance of the containers are based on assumed criteria and simple testing and analysis. This approach is not as rigorous as regulatory Type $\mathrm{B}$ container qualification; and the quality of these containers will not be equivalent to certified Type B containers, even though the performance is predicted to be similar. 
Appendix E-Memo from Kay

Matsurnoto (LANL) on ARG

Thermal Modeling 
Los Alamos

WATIOOAL LABORA OOAY

memorandum

WX-11 Andyels and Teating Group, MS Co31

Los Alamos, Now Mexico 87545
ToMs: Max Kelly / MS C936

Fromms: Kay Matsumoto / MS C931

PhoneFAX: (505)665-5906/(505)665-5127

Symbol: WX-11-93-1

Date: March 30, 1993

\section{SUBJECT: EXPLO THERMAL MODELING - ARG FY93 FIRST HALF STATUS REPORT}

Thermal modeling of Los Alamos weapons in stockpile has been completed. Details on the analyses and results are explained in classified documents WX-11-92-147 and WX-11-93-18 titled "EXPLO Thermal Analysis of Weapons in Stockpile (U)" and "Collection of EXPLO Models and Results from the ARG Thermal Analysis of Weapons in Stockpile(U)", respectively.

The following weapon systems were modeled:

$\begin{array}{llll}\text { B28 } & \text { B43 } & \text { B53 } & \text { B54 } \\ \text { B57 } & \text { B61-0,1 } & \text { B61-2,5 } & \text { B61-3,4 } \\ \text { W44 } & \text { W50 } & \text { W69 } & \text { W76 } \\ \text { W78 } & \text { W80 } & \text { W85 } & \text { W88 }\end{array}$

The objective is to have the models readily ava: ic to make a reliable assessment of the vulnerability of a weapon involved in an accident or emergency situation. Five sets of 1-D thermal models were created:

1) weapons, bare and in reentry vehicles (RVs)

2) weapons in shipping containers

3) weapons in M483 damaged weapon shipping containers

4) weapons in M511 damaged weapon shipping containers

5) weapons in H1501 Transportation Accident Resistant Containers (TARCs)

The models were exposed to a $1000^{\circ} \mathrm{C}$ fire accident scenario using the explosives thermal analysis computer code, EXPLO. EXPLO is a one-dimensional code that uses the finite difference method to calculate temperatures and times to ignition of explosive materials. EXPLO predicts ignition when the high explosive (HE) has reached a critical temperature and energy level required for a runaway thermal reaction.

The thermal models are based on cross sections through the equator of the primaries. The models are spherical because of the symmetry of the weapons. Self-heating from plutonium, tritium bottles, and/or Radioisotopic Thermal Generators (RTGs) is included in the models. 
This table shows the EXPLO models of Los Alamos weapons in stockpile. Many of the systems were modeled with two different types of pits as shown in the table. Not eyery weapon system is shipped in a shipping container. The bombs are generally shipped bare on cradles with tiedowns. Also, weapons that do not fit in the H1501 are not modeled. These models will be available for analysis using the actual scenario of an accident should one occur.

\begin{tabular}{|c|c|c|c|c|c|c|c|}
\hline no. & system & pit/RV & bare/RV & $\begin{array}{l}\text { shipping } \\
\text { container }\end{array}$ & M483 & M511 & H1501 \\
\hline 1 & B28 & $83 \mathrm{pit}$ & $X$ & & $\mathrm{X}$ & $X$ & $\mathbf{X}$ \\
\hline 2 & & 93 pit & $X$ & & $X$ & $X$ & $X$ \\
\hline 3 & B43 & 79 pit & $X$ & & $X$ & $X$ & $\mathrm{X}$ \\
\hline 4 & & 101 pit & $X$ & & $X$ & $X$ & $X$ \\
\hline 5 & B53 & $76 \mathrm{pit}$ & $X$ & $X$ & $X$ & $\mathrm{X}$ & \\
\hline 6 & B54 & 81 pit & $X$ & & $X$ & $X$ & $X$ \\
\hline 7 & & 96 pit & $X$ & & $X$ & $X$ & $X$ \\
\hline 8 & B57 & $\bmod 1$ & $X$ & & $X$ & $X$ & $\mathrm{X}$ \\
\hline 9 & & $\bmod 2$ & $X$ & & $X$ & $X$ & $X$ \\
\hline 10 & B61 & $\bmod 0 \& 1$ & $X$ & & $X$ & $X$ & $X$ \\
\hline 11 & & $\bmod 2 \& 5$ & $X$ & & $\mathrm{X}$ & $X$ & $X$ \\
\hline 12 & & $\bmod 3 \& 4$ & $X$ & & $X$ & $\mathrm{X}$ & $X$ \\
\hline 13 & W44 & $74 \mathrm{pt}$ & $\mathrm{X}$ & & $X$ & $\mathrm{X}$ & $X$ \\
\hline 14 & & 100 pit & $X$ & & $X$ & $\mathrm{X}$ & $X$ \\
\hline 15 & W50 & 92 pit & $X$ & $X$ & $X$ & $X$ & $X$ \\
\hline 16 & & 103 pit & $X$ & $X$ & $X$ & $X$ & $X$ \\
\hline 17 & W69 & bare & $X$ & $X$ & $X$ & $X$ & $X$ \\
\hline 18 & & $\mathrm{RV}$ & $X$ & & $X$ & $X$ & $X$ \\
\hline 19 & W76 & 116 pit & $X$ & $X$ & $X$ & $X$ & $X$ \\
\hline 20 & W78 & 117 pit & $X$ & $X$ & $X$ & $\mathrm{X}$ & $X$ \\
\hline 21 & W80 & bare & $X$ & $X$ & $X$ & $\mathrm{X}$ & $X$ \\
\hline 22 & & 119 pit - CM & $X$ & & $X$ & $\mathrm{X}$ & \\
\hline 23 & & 120 pit - ALCM & $\mathrm{X}$ & & $\mathrm{X}$ & $\mathrm{X}$ & $X$ \\
\hline 24 & W85 & bare & $\mathrm{X}$ & & $\mathrm{X}$ & $\mathrm{X}$ & $X$ \\
\hline 25 & & RV & $\mathrm{X}$ & $\mathrm{X}$ & $\mathrm{X}$ & $\mathrm{X}$ & \\
\hline 26 & W88 & Mk5 & $\mathrm{X}$ & $\mathrm{X}$ & $\mathrm{X}$ & $\mathrm{X}$ & $\mathrm{X}$ \\
\hline
\end{tabular}

As requested in your memo, I estimate 0.75 FTE for my ARG work. I believe the EXPLO thermal analysis would be in the Capability Development category.

Please call me if you have any questions.

Cy:

$\begin{array}{lll}\text { Ron Flury } & \text { WX-11 } & \text { MS C931 } \\ \text { Paul Smith } & \text { WX-11 } & \text { MS C931 } \\ \text { Kay Matsumoto } & \text { WX-11 } & \text { MS C931 }\end{array}$


Appendix F-Containment Vessel

Assembly and Leak Test Instructions 


\title{
CONTAINMENT VESSEL ASSEMBLY INSTRUCTIONS
}

\section{Laboratory Supplies and Equipment Required}

\author{
Isopropyl Alcohol \\ Rubber Gloves \\ Kimwipes \\ Cotton Applicators \\ Vacuum Grease \\ Torque Wrenches \\ 80 pound feet range \\ 75 pound inch range \\ Hand Tools - \\ $1 / 4$ " and $3 / 8$ " square drive ratchet \\ $9 / 16^{\prime \prime}$ and $5 / 8$ " deep sockets \\ $3 / 8$ " square drive extension bars \\ $1 / 4$ " hex head drivers
}

\section{Torque Specifications}

Sample Valve Hex Handle Nut $=30 \pm 2 \mathrm{lb}$-in

Leak Test Fitting Cap $=60 \pm 5 \mathrm{lb}$-in

Adapter Plate and Lid Socket Head Cap Screws $=20 \pm 5 \mathrm{lb}$-ft. 


\section{CONTAINMENT VESSEL ASSEMBLY}

The following steps describe the procedure to be followed to assemble the Cuntainment Vessel.

010 Clean the interior surfaces of the containment vessel body using isopropyl alcohol, and examine the surfaces for visual defects.

020 Clean the containment vessel flange area, 0 -ring grooves, and inner and outer 0 -rings (15.440" dia and 14.400" dia) using isopropyl alcohol. Examine the parts for visual defects.

030 Apply vacuum grease to inner and outer O-rings.

040 Install the inner and outer O-rings in the containment vessel flange.

050 Clean the interior and O-ring sealing surfaces of the adapter plate using isopropyl alcohol. Examine the adapter plate and O-ring sealing surfaces for visual defects.

060 Install the adapter plate on the containment vessel body and verify that the vessel screw holes are aligned.

070 Install the twelve (12) vessel screws (part number 394789). Tighten the screws using a 1/4" hex head driver and $3 / 8^{\prime \prime}$ square drive ratchet. Torque the screws to $20 \pm 2$ pound feet, using a $1 / 4^{n}$ hex head driver and $3 / 8^{n}$ square drive torque wrench in a diametrically opposed, alternating sequence.

080 Clean the exterior surfaces of the adapter plate, 0 -ring grooves, and inner and outer 0 -rings $\left(10.680^{\mathrm{N}}\right.$ dia and 9.030" dia) using isopropyl alcohol. Examine the parts for visual defects.

090 Install the inner and outer O-rings in the adapter plate.

100 Clean the interior and O-ring sealing surfaces of the containment vessel lid using isopropyl alcohol. Examine the adapter plate and O-ring sealing surfaces for visual defects.

110 Install the containment vessel lid on the adapter plate and verify that the vessel screw holes are aligned.

120 Install the twelve (12) vessel screws (part number 394789). Tighten the screws using a $1 / 4^{\text {" }}$ hex head driver and $3 / 8^{n}$ square drive ratchet. Torque the screws to $20 \pm 2$ pound feet, using a $1 / 4^{\prime \prime}$ hex head driver and $3 / 8^{\prime \prime}$ square drive torque wrench in a diametrically opposed, alternating sequence.

130 After conducting the Containment Vessel Carbon Dioxide Backfill and Leak Tests verify that the Sample the Sample Valve Hex Handle Nut is torqued to $30 \pm 2 \mathrm{lb}$-in and that the leak test fitting caps on the adapter plate and containment vessel lid are torqued to $60 \pm 5 \mathrm{lb}$-in 


\section{LEAK TESTING INSTRUCTIONS}

The following three leak tests are required to certify the proper assembly of the containment vessel.

\section{SAMPLE VALVE LEAK TEST}

This test verifies that the sample valve seat is properly sealing.

Remove the sample fitting stem protector and attach the leak test line from the T553 to the sample fitting.

Verify that the sample valve is CLOSED and that the sample valve nut is torqued to $30 \pm 2$ in-lb.

Evacuated the sample fitting and sample port passage by rotating the CONTROL VALVE to the PUMP position and waiting until the LED display indicates less than 0.10 Torr.

Begin the test by rotating the CONTROL VALVE to the OFF/TEST position and then press and release the START TEST switch on the front panel of the T553.

The T553 responds by lighting the TEST IN PROGRESS lamp.

After the test is complete, the TEST IN PROGRESS lamp turns off and the T553 indicates a PASS or FAIl condition by lighting either the green PASS front panel lamp or the red FAIl front panel light.

If the leak test passed, remove the T553 leak test line from the sample fitting and reinstall the sample fitting stem protector.

If the leak test failed, the leak test should be repeated. If the leak test fails the second time:

Check the T553 - perform the T553 self-diagnostic test and reset zero.

Check the Valve and fitting torque - $30 \pm 2$ in-lb for the valve nut and 40 $\pm 2 \mathrm{ft}-\mathrm{lb}$ for the sample fitting valve retainer nut

Clean the sealing surfaces - remove the lid, remove and clean the 0 rings, and reassemble.

Repeat the leak test

Replace the O-rings

Replace the sample fitting 


\section{CONTAINMENT VESSEL BODY/ADAPTER PLATE - O-RING LEAK TEST}

This test verifies that the 0 -rings between the containment vessel body and the adapter plate are properly sealing.

Remove the leak test fitting cap and attach the leak test fitting adapter to the leak test fitting. Tighten the leak test fitting adapter finger tight and then tighten it another $1 / 8$ to $1 / 4$ turn.

Attach the leak test line on the T553 to the leak test fitting adapter.

Evacuated the volume between the 0 -rings by rotating the CONTROL VALVE to the PUMP position and waiting until the LED display indicates less than 0.10 Torr.

Begin the test by rotating the CONTROL VALVE to the OFF/TEST position and then press and release the START TEST switch on the front panel of the T553.

The T553 responds by lighting the TEST IN PROGRESS lamp.

After the test is complete, the TEST IN PROGRESS lamp turns off and the T553 indicates a PASS or FAIl condition by lighting either the green PASS front panel lamp or the red FAII front panel light.

If the leak test passed, remove the T553 leak test line from the leak test fitting adapter, remove the leak test fitting adapter from the leak test fitting, and install the leak test fittin ${ }_{\breve{G}}$ cap. Finger tighten the leak test fitting cap and then torque it to $60 \mathrm{in}-\mathrm{lb}$.

If the leak test failed, the leak test should be repeated. If the leak test fails the second time:

Check the T553 - perform the T553 self-diagnostic test and reset zero.

Check the leak test fitting torque $-40 \pm 2 \mathrm{ft}$-lb

Clean the sealing surfaces - remove the lid, remove and clean the 0rings, and reassemble.

Repeat the leak test

Replace the O-rings

Replace the leak test fitting 


\section{CONTAINMENT VESSEL LID - O-RING LEAK TEST}

This test verifies that the 0 -rings between the containment vessel lid and the adapter plate are properly sealing.

Remove the leak test fitting cap and attach the leak test fitting adapter to the leak test fitting. Tighten the leak test fitting adapter finger tight and then tighten it another $1 / 8$ to $1 / 4$ turn.

Attach the leak test line on the T553 to the leak test fitting adapter.

Evacuated the volume between the 0 -rings by rotating the CONTROL VALVE to the PUMP position and waiting until the LED display indicates less than 0.10 Torr.

Begin the test by rotating the CONIROL VALVE to the OFF/TEST position and then press and release the START TEST switch on the front panel of the T553.

The T553 responds by lighting the TEST IN PROGRESS lamp.

After the test is complete, the TEST IN PROGRESS lamp turns off and the T553 indicates a PASS or FAII condition by lighting either the green PASS front panel lamp or the red FAII front panel light.

If the leak test passed, remove the T553 leak test line from the leak test fitting adapter, remove the leak test fitting adapter from the leak test fitting, and install the leak test fitting cap. Finger tighten the leak test fitting cap and then torque it to 60 in-lb.

If the leak test failed, the leak test should be repeated. If the leak test fails the second time:

Check the T553 - perform the T553 self-diagnostic test and reset zero.

Check the leak test fitting torque $-40 \pm 2 \mathrm{ft}-\mathrm{lb}$

Clean the sealing surfaces - remove the lid, remove and clean the 0 rings, and reassemble.

Repeat the leak test

Replace the O-rings

Replace the leak test fitting 


\section{DISTRIBUTION}

J.W. Tomes

Mason and Hanger-Silas Mason Co., Inc.

Pantex Plant

Highway 60, FM 2373

P.O. Box 30020

Amarillo, TX 79177

Tom Williams

WX-1

Los Alamos National Laboratory

Los Alamos, NM 87545

Louise O'Brien

WX-11

Los Alamos National Laboratory

Los Alamos, NM 87545

Del Cruff

L-125

Lawrence Livermore National Laboratory

Livermore, CA

1 DOE/AL/WEMD J. Stickney

1 DOE/AL/NESD S.E. Wright

$5331 \quad$ J.P. Hoffman

$1331 \quad$ S.D. Spray

$15165 \quad$ R.L. Alvis

$15165 \quad$ R.E. Glass

$15165 \quad$ D.H. Hill

$55165 \quad$ A.R. York

$15365 \quad$ G.C. Story

$57141 \quad$ Technical Library

$17151 \quad$ Technical Publications

10 7613-2 Processing for DOE/OSTI

1 8523-2 Central Technical Files 
